\title{
Constraining the relationships between aerosol height, aerosol optical depth and total column trace gas measurements using remote sensing and models
}

\author{
Shuo Wang ${ }^{1}$, Jason Blake Cohen ${ }^{1,2}$, Chuyong Lin $^{1}$, and Weizhi Deng ${ }^{1}$ \\ ${ }^{1}$ School of Atmospheric Sciences, Sun Yat-Sen University, Zhuhai, 519000, China \\ ${ }^{2}$ Southern Marine Science and Engineering Guangdong Laboratory, Zhuhai, 519000, China
}

Correspondence: Jason Blake Cohen (jasonbc@alum.mit.edu)

Received: 8 November 2019 - Discussion started: 12 February 2020

Revised: 10 October 2020 - Accepted: 12 October 2020 - Published: 11 December 2020

\begin{abstract}
Proper quantification of the aerosol vertical height is essential to constrain the atmospheric distribution and lifetime of aerosols, as well as their impact on the environment. We use globally distributed, daily averaged measurements of aerosol stereo heights of fire aerosols from the Multiangle Imaging SpectroRadiometer (MISR) to understand the aerosol distribution. We also connect these results with a simple plume rise model and a new multi-linear regression model approach based on daily measurements of $\mathrm{NO}_{2}$ from OMI and CO from MOPITT to understand and model the global aerosol vertical height profile over biomass burning regions. First, plumes associated with the local dry-burning season at midlatitudes to high latitudes frequently have a substantial fraction lofted into the free troposphere and in some cases even the stratosphere. Second, plumes mainly associated with less-polluted regions in developing countries and heavily forested areas tend to stay closer to the ground, although they are not always uniformly distributed throughout the boundary layer. Third, plumes associated with more serious loadings of pollution (such as in Africa, Southeast Asia and northeast China) tend to have a substantial amount of smoke transported uniformly through the planetary boundary layer and up to around $3 \mathrm{~km}$. Fourth, the regression model approach yields a better ability to reproduce the measured heights compared to the plume rise model approach. This improvement is based on a removal of the negative bias observed from the plume model approach, as well as a better ability to work under more heavily polluted conditions. However, over many regions, both approaches fail, requiring
\end{abstract}

deeper work to understand the physical, chemical and dynamical reasons underlying the failure over these regions.

\section{Introduction}

Over the past few decades, there has been an increasing amount of research into the spatial and temporal distribution of atmospheric aerosols (Achtemeier et al., 2011; Cohen et al., 2017, 2018). This has been in part because of the impacts that aerosols have on clouds, radiation, the atmospheric energy balance and climate, human health, and ecosystems, among other aspects (Cohen, 2014; Tao et al., 2012; Ramanathan et al., 2007; Ming et al., 2010). However, there has not been a significant amount of research work done in terms of understanding the vertical distribution of aerosols in the atmosphere (Cohen et al., 2018), although such knowledge is essential to constrain their impacts on the atmospheric energy budget (Kim et al., 2008; Grandey et al., 2018), circulation, clouds and precipitation (Cohen and Prinn, 2011; Tosca et al., 2011; Singh et al., 2018), and ultimately tropospheric distribution (Leung et al., 2007; Randles et al., 2017). Largescale reviews of the biomass burning literature spend a lot of time on how the atmosphere impacts the burning conditions but also tend to overlook the issue of how the emissions are rapidly vertically distributed upon being emitted (PalaciosOrueta et al., 2005).

The vertical distribution of aerosols is observed to be more complex than the present generation of global and mesoscale models are capable of reproducing in regions where there 
are multiple sources with similar magnitudes and very different vertical lofting properties (Kahn et al., 2008; Petrenko et al., 2012; Chew et al., 2013). While on the one hand urban sources are emitted with relatively low amounts of heat and are therefore known to remain in the boundary layer (Guo et al., 2016), on the other hand, biomass burning sources are emitted with large amounts of heat at high temperature and frequently are rapidly transported higher in the atmosphere, such that they are effectively emitted at height (Ichoku et al., 2008; Field et al., 2009; Freeborn et al., 2014). Furthermore, there are other forcing mechanisms, such as deep convection (Petersen and Rutledge, 2001; Turquety et al., 2007), volcanos (Singh et al., 2018; Flower and Kahn, 2017), mountain slope winds (Cohen et al., 2017) and other dynamical forcings (Cohen and Prinn, 2011; Tosca et al., 2011), which also have a substantial effect on the vertical distribution of aerosols over specific spatial and temporal scales. The vertical distribution of aerosols has a direct impact on their lifetime and hence atmospheric loading, with aerosols lofted above the boundary layer having a significantly larger impact on the atmosphere than those emitted into the boundary layer (Nelson et al., 2013; Paugam et al., 2016). Therefore, understanding the vertical distribution over the source regions (Nelson et al., 2013) of aerosols and how this may change over time is absolutely critical for our being able to better constrain the environmental and atmospheric impacts.

Currently, aerosol data come from different measurements obtained at the surface, in balloons, on aircraft and via satellites, each with varying degrees of accuracy (Husar et al., 1997; Jost et al., 2004; Rogers et al., 2011). Jost et al. (2004) used in situ measurements to observe the plume from North American fires emitted at a surface temperature above $380 \mathrm{~K}$, and they found that carbon monoxide and tiny particles were detected in the stratosphere at an altitude of $15.8 \mathrm{~km}$. Kahn et al. (2007) found using Multi-angle Imaging SpectroRadiometer (MISR) measurements that $5 \%$ to $18 \%$ of smoke plumes reached the free troposphere over Alaska and the Yukon Territories in 2004. Winker et al. (2013) introduced the idea of possibly using CALIPSO lidar as a measurement technique, since it is more sensitive to dispersed vertical aerosols away from fire points than MISR satellites and therefore could capture the overall smoke cloud better. Val Martin et al. (2018) used MISR data with pixel-weighted and aerosol optical depth (AOD)-weighted statistics to estimate the impact of fire severity on fire height and found that while in the Arctic there were significant areas with aerosols found above the boundary layer, in agricultural areas and most other non-arctic areas, the amount was small or nonexistent. Cohen et al. (2018) produced the first comprehensive study using CALIPSO lidar data anywhere in the world and found that throughout the 2006 biomass burning season in Southeast Asia $51 \%$ to $91 \%$ of smoke from fires was ultimately found to reside in the free troposphere. This is consistent with an earlier theory which shows that when a plume is injected into the free troposphere, it tends to accumulate in a relatively stable layer (Val Martin et al., 2010; Kahn et al., 2007).

The present generation of models have not been found to reproduce the vertical distribution of aerosols very well (Val Martin et al., 2012; Paugam et al., 2016; Cohen et al., 2018). Most of the previous approaches to simulate convection induced by a fire or other surface heat sources have been performed with simplified models (Briggs, 1965; Trentmann et al., 2006). There have been multiple studies using global and regional chemical transport models (CTMs) with such simple plume models built in to try to understand the impact of fire emissions on air quality and atmospheric composition (Pfister et al., 2008; Turquety et al., 2007; Spracklen et al., 2009; Ichoku and Ellison, 2014). There have also been other attempts to simulate the impacts of different vertical distributions based on higher-resolution wind pattern profiles, done on a region-by-region basis (Cohen and Prinn, 2011; Cohen and Wang, 2014). More recently, people have attempted to use Lagrangian models such as those of DeWitt et al. (2019) and Vernon et al. (2018) to understand how knowledge of air mass flows could better contribute to the understanding of different vertical regions having material from biomass burning plumes found far upwind. Val Martin et al. (2012) used a 1-D plume rise model to study plume heights over North America, which demonstrated dynamical heat flux and atmospheric stability structure affect plume rise. Cohen et al. (2018) also adapted a plume rise model and found that significant enhancements were required to the measured fire radiative power (FRP) values in order to match the mean values of measured heights, although the upper and lower quartiles were not able to be successfully reproduced. At present, there is no known modeling work that can accurately and consistently reproduce this substantial atmospheric loading found throughout different regions of the world in the upper boundary layer and free troposphere.

Biomass combustion is a major source of trace gases and aerosols in the atmosphere as well as having an important impact on tropospheric ozone formation. The vast majority of biomass burning in the tropics and nontropical agricultural regions of the world is a human-driven activity (Kauffman et al., 2003; Achtemeier et al., 2011; Paugam et al., 2016), while in certain arctic regions, lightning accounts for a significant amount of biomass burning (Generoso et al., 2007). In particular, this activity has been shown to have a strong annual cycle (Cohen et al., 2017; Labonne et al., 2007; Tsigaridis et al., 2014). The process of burning releases heat, increasing the local temperature of the surrounding air and resulting in a change in buoyancy and an ensuing updraft above the heat-producing area. Based on how long the plume maintains its buoyancy, it will rise to a fairly high position in the atmosphere. However, strong turbulence causes the plume to mix with the surrounding air, reducing plume temperature and buoyancy, eventually reaching a stable layer at which the updraft stops (Damoah et al., 2006; Freitas et al., 2007). For these reasons, a significant amount of the material emitted 
from biomass combustion is lofted above the surface, compared with urban sources, where almost all of the aerosol remains near the surface (Ichoku et al., 2008; Cohen and Prinn, 2011). This point is important because if aerosol is injected into the atmosphere above the planetary boundary layer (PBL) it can be carried by the faster free-tropospheric winds farther away, leading to a larger impact on the atmosphere (Vernon et al., 2018; Nelson et al., 2013).

The present generation of models has difficulty reproducing the actual vertical distribution of atmospheric aerosols when addressing cases that do not tend to have a combination of a highly energetic fire source, a relatively dry atmosphere and a relatively optically thin smoke column emitted by the fire. One reason stems from the fact that in situ production and removal mechanisms of aerosols and the distribution of rainfall are not fully understood (Tao et al., 2012), all of which weaken the ability of simple plume rise models to reproduce the vertical distribution of aerosols (Urbanski, 2014; Cohen et al., 2017). In addition, heterogeneous aerosol processing associated with the highly polluted conditions within the atmospheric plume may also change the hygroscopicity, which in turn impacts the washout rate and vertical distribution of the aerosols (Kim et al., 2008; Cohen et al., 2011). On top of this, highly polluted aerosol loadings, especially so for absorbing aerosols as found in fires, lead to changes in the radiative equations and the vertical atmospheric stability (Guo et al., 2019; Cohen et al., 2018; Zhu et al., 2018). Furthermore, small-scale convective events and large-scale circulation patterns are generally not both well produced by the same scale models, leading to an inherent bias against one or the other convection-producing source (Winker et al., 2013; Jost et al., 2004). In summary these factors can lead to actual changes in the vertical distribution of aerosols that simple models are not able to reproduce, including those which have used inverse modeling with a fixed vertical a priori (i.e., Heald et al., 2004; Cohen and Prinn, 2011), in turn affecting the distribution of aerosols hundreds to thousands of kilometers downwind, supporting new measurement-based perspectives (i.e., Kahn, 2020).

This work describes a new approach to comprehensively understand global-scale, daily measurements of the vertical distribution of aerosols and introduces a simple modeling approach better capable of reproducing the vertical distribution of smoke aerosols emitted by biomass burning. First, we analyze the plume heights from 3.5 years of daily Multi-angle Imaging SpectroRadiometer (MISR) satellite measurements, separating the more than 67000 measurements by the magnitude of the measured variability. Next we build aerosol plume injection models depending on the region, terrain, land type and geospatial properties. We use this simple plume model to show that the aerosol injection heights are underestimated. We then apply a linear statistical model and show that including measurements of column gas loadings from other satellites in combination with the meteorological and FRP measurements produces a better match. We imply that ignor- ing the magnitude of the source emissions is an important factor in the plume rise height, another factor which the current generation of models does not take into consideration. We also demonstrate that improvements in the local convective transport process and direct and semi-direct effects of aerosols are needed to further reduce the error between the models and measurements.

It is hoped that these results will provide insights to further improve our understanding of the vertical distribution of aerosols, both from the modeling side and as far as what sources of information are best required from the measurement community to help the modelers improve their understanding. We also provide a unique perspective on the connections between air quality and the vertical distribution of particulate matter, allowing the community to make further advances in these fields as well as associated issues of longrange transport of aerosols.

\section{Methodology}

\subsection{MISR aerosol height measurements}

MISR, the Multi-angle Imaging SpectroRadiometer, is an instrument flying on the Terra satellite capable of recording images at nine different angles over four bands at 446, 558, 672 and $866 \mathrm{~nm}$. The cameras point forward, downward and aftward, allowing images to be acquired with nominal view angles, relative to the surface of $0, \pm 26.1, \pm 45.6, \pm 60.0$ and $\pm 70.5^{\circ}$. All cameras have a track width of $360 \mathrm{~km}$ and observations extending within $\pm 81^{\circ}$ latitude (Kahn et al., 2007).

In this paper, we use the MISR INteractive eXplorer (MINX) software, which captures the plume height from the MISR image and combines it with the MODIS fire point measurements (also taken on the Terra satellite). The software then calculates the wind speed and the elevation of contrast elements globally over a $1.1 \mathrm{~km}$ pixel area, providing a digitization of wildfire smoke plume height (Val Martin et al., 2010; Kahn et al., 2007; Nelson et al., 2013).

\subsection{Geography}

Around the world, biomass burning and deforestation have undergone tremendous changes in the past few decades, with current extremes making the news in many places throughout the world. To better interpret the land use conditions in the biomass burning areas, we apply global land-cover type data of 18 different vegetation types, as measured in 2015 in Fig. 1. This work specifically focuses on those areas where the land type has undergone known significant changes from forest to agriculture, or from forest or agriculture to urban, as demonstrated in the black boxes in Fig. 1.

Considering MISR daily plume heights (where the $1.1 \mathrm{~km}$ pixels are first averaged to $10 \mathrm{~km} \times 10 \mathrm{~km}$ grids) throughout the globe, we have determined that the respective average and standard deviation of the plume height over the 3.5 years 


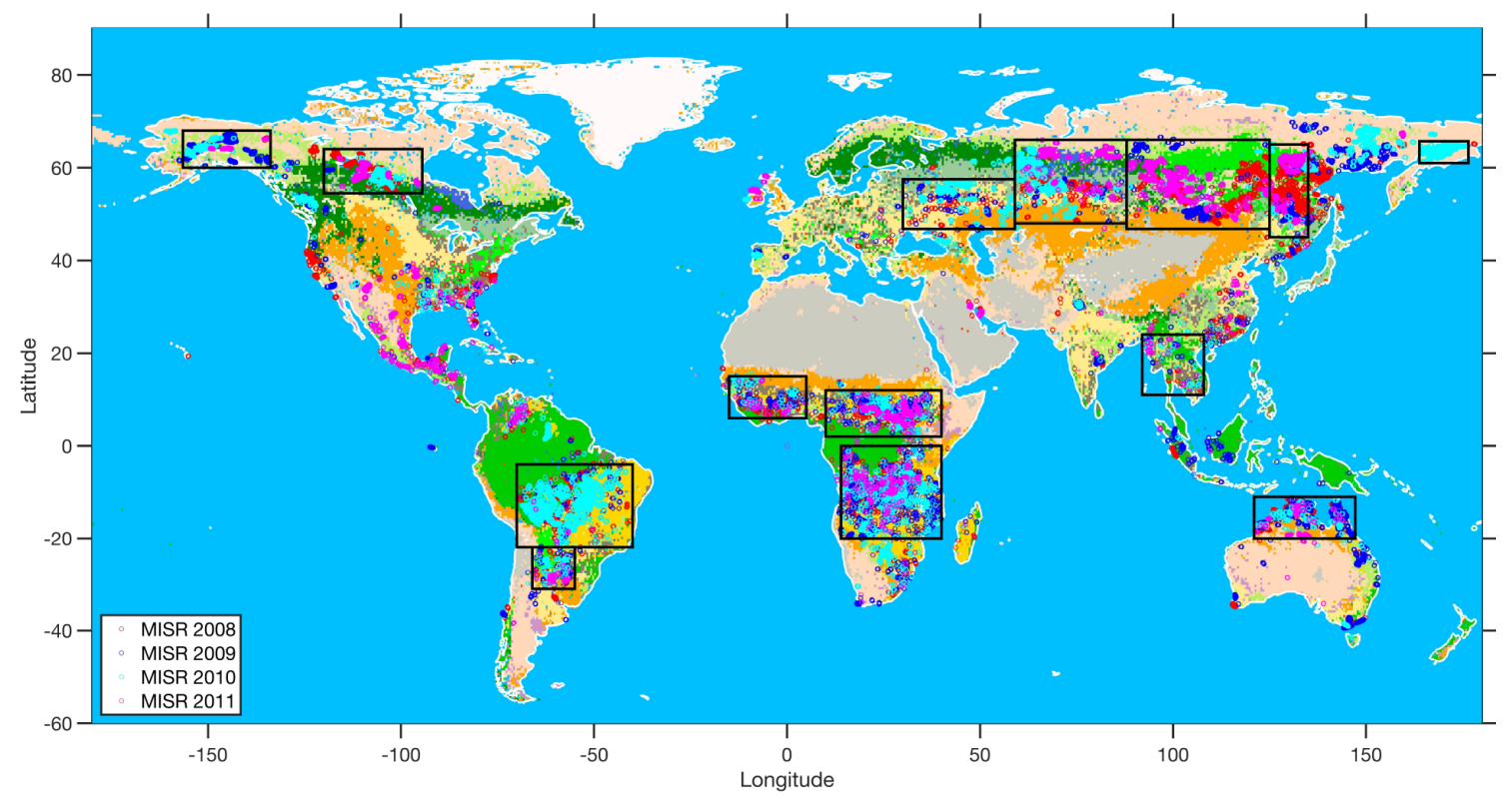

\begin{tabular}{|lll|}
\hline Water & $\square$ Closed Shrublands & Croplands \\
Evergreen Needleleaf Forest & $\square$ Open Shrublands & Urban and Built-up \\
Evergreen Boradleaf Forest & $\square$ Woody Savannas & $\square$ Cropland/Nature Vegetation Mosaic \\
\begin{tabular}{|l|} 
Deciduous Needleleaf Forest \\
Deciduous Boradleaf Forest \\
Mixed forest
\end{tabular} & $\square$ Savannas and Ice \\
\hline Garren or Sparsely Vegetated & $\square$ Missing \\
\hline
\end{tabular}

Figure 1. Land surface type at each of the daily MISR measurements from January 2008 to June 2011. Each dot corresponds to an individual aerosol plume, with different colors representing different years.

of MISR daily measurements (from 1 January 2008 through 30 June 2011) are 1.37 and $0.72 \mathrm{~km}$. However, over our regions of interest, we find that we are able to capture the large bulk of the standard deviation globally, as demonstrated in Table S1 in the Supplement.

The geographical data yield us a few conclusions about those regions which have the largest contribution to the biomass burning height variation. First, they are distributed in the middle and low latitudes (between the Tropic of Cancer and the Tropic of Capricorn) and/or high latitudes (near the Arctic Circle). Second, they tend to occur in regions of more rapid economic growth and/or in regions which are experiencing the most rapid change in land surface temperature.

\subsection{MOPITT carbon monoxide (CO) measurements}

Carbon monoxide (CO) is a colorless and odorless gas that plays a major role in moderating the chemistry of the Earth's atmosphere as well as having a deleterious effect on human health. One of the world's major sources of $\mathrm{CO}$ is emissions from biomass burning (Lin et al., 2020b). For these reasons, we obtain measurements of CO from the MOPITT satellite (an instrument mounted on NASA's Terra satellite), which has collected data since March 2000. MOPITT's resolution is $22 \mathrm{~km}$ at nadir and observes the Earth in swaths that are $640 \mathrm{~km}$ wide.

In terms of the CO from MOPITT, we take the daytimeonly retrievals (to reduce bias) from version 8 , level 3 data, from 1 January 2008 through 30 June 2011. Specifically we use the combined thermal and near-infrared product (Deeter et al., 2017). We further constrain the data to where the cloud fraction is less than 0.3 and where the vertical degrees of freedom are larger than 1.5. This combination has been shown to allow us to trust that there is a sufficient amount of signal and knowledge to demonstrate an actual measurement in the vertical, compared with a result only dependent on the a priori model, as shown in Lin et al. (2020a). There are further gaps in the data due to orbital locations and very high aerosol conditions, all of which prevent entire coverage of our areas of interest each day. Therefore, we average all of the individual MOPITT data that pass our test to a $1^{\circ} \times 1^{\circ}$ grid.

\subsection{OMI nitrogen dioxide $\left(\mathrm{NO}_{2}\right)$ measurements}

Another chemical species co-emitted by biomass burning with aerosols and $\mathrm{CO}$ is $\mathrm{NO}_{2}$ (Seinfeld and Pandis, 1998). For this reason, we also use the daily average total column loading of $\mathrm{NO}_{2}$ as measured by the Ozone Monitoring Instru- 
ment (OMI). Specifically we use version 3 level 2 measurements taken from the Aura satellite (Boersma et al., 2007; Lamsal et al., 2011; Levelt et al., 2006), which has ground pixel sizes ranging from $13 \mathrm{~km} \times 24 \mathrm{~km}$ at nadir to about $13 \mathrm{~km} \times 150 \mathrm{~km}$ at the outermost part of the swath. In terms of the $\mathrm{NO}_{2}$ from $\mathrm{OMI}$, we first take the daily retrievals under the conditions where the cloud fraction is less than 0.3. Next, we aggregate the data to $0.25^{\circ} \times 0.25^{\circ}$ using a linear interpolation and area-weighted approach. In this way, those measurements near the edge of the swath or which are adjacent to cloudy areas are weighted less heavily in terms of the merged product. However, the areas are sufficiently large as to be roughly representative of the emissions from biomass burning of the $\mathrm{NO}_{2}$ from within the grid box, compared to that transferred from adjacent grid boxes.

One advantage of the OMI $\mathrm{NO}_{2}$ column measurements is that they can often be observed under relatively cloudy or smoky conditions (Lin et al., 2014). Another advantage is that the atmospheric lifetime of $\mathrm{NO}_{2}$ is only a few hours, and therefore relatively large changes in the temporal-spatial distribution of $\mathrm{NO}_{2}$ column measurements are highly correlated with wildfire sources (Lin et al., 2020a; He et al., 2020). $\mathrm{NO}_{2}$ has another interesting property in that its production and emissions are a strong function of the temperature at which the fires are burning, since $\mathrm{NO}_{2}$ is formed based on the air temperature (Seinfeld and Pandis, 1998).

\subsection{Plume rise model}

Although emissions from biomass burning are similar to those from urban combustion sources, there are two major differences, arising from the much higher burning temperature and the environment in which the combustion occurred. This ensures that a significant amount of the emissions from biomass burning will be transported upwards due to the positive buoyancy generated by the fire. Due to the confluence of both local and nonlocal dynamical forcing in situ, the ultimate height reached by these emissions is a complex function of the local fire energy and both the local and large-scale meteorology at the time of combustion. While the aerosol particles are immediately transported horizontally by the largescale winds, their vertical rise will only stop once their local buoyancy has reached equilibrium and any dynamical motion has degraded back to the background conditions (Freitas et al., 2007; Sofiev et al., 2012; Val Martin et al., 2018).

To approximate this rise, we use a simple plume rise model (Briggs, 1965) to generate the final injection height of the biomass burning emissions based on the buoyancy and horizontal velocity of the plume and various atmospheric conditions. Although this model is based on an empirical formula mathematically, it is essentially a thermodynamic approximation (Cohen et al., 2018) which costs much less computationally as well as being quite efficient when the biomass burning source covers a large area.
In theory, if such an approach was successful, and it was given appropriate environmental data, it should be able to reproduce the heights derived from the MISR multi-angle measurements. For this reason, we use a 1-D plume rise model to independently predict the position and height of each measured MISR plume at each $10 \mathrm{~km} \times 10 \mathrm{~km}$ grid which is found to have measurements. To initialize the model, we require meteorological data as well as MODIS hot-spot information.

\subsection{NCEP reanalysis data}

NCEP and NCAR produce an analysis and prediction system to produce a meteorological field analysis of the 6-hourly state of the atmosphere from 1948 to the present. The measurements incorporated into this approach include groundbased, in situ and remotely sensed sources, while the modeling aspect is based on state-of-the-art meteorological models. Daily data for each day which has MISR data are obtained from the reanalysis version 1 (Kalnay et al., 1996). Only data required to run the plume rise model are used: the vertical temperature and pressure distributions, the surface air temperature, and the initial vertical velocity of the smoke emissions $(\mathrm{d} P / \mathrm{d} t)$. The vertical temperature gradient $(\mathrm{d} T / \mathrm{d} z)$ and the vertical velocity $(\mathrm{d} z / \mathrm{d} t)$ are computed from these data.

\subsection{Regression model}

Linear regression is a simple method by which one can relate the impact that a set of orthogonal inputs has in terms of reproducing measured environmental values. It does not imply causation, merely demonstrating that the input values behave in a similar manner. However, when looking to describe whether or not a new variable has a substantial amount of correlation with a given phenomenon, it can be found to be very useful.

In this case, we are interested to see if the loadings of $\mathrm{NO}_{2}$ and $\mathrm{CO}$ are related to the heights of the fires. There is a strong physical case to be made here, since both are directly emitted by the fires themselves. Furthermore, the underlying causes of these substances are different: $\mathrm{NO}_{2}$ is a function of the fire temperature, while $\mathrm{CO}$ is a function of the oxygen availability. Furthermore, these are proxies for radiatively active substances such as soot and ozone.

For our work, we have decided to apply a simple linear regression model of the wind speed, FRP, $\mathrm{CO}, \mathrm{NO}_{2}$ and the ratio of $\mathrm{NO}_{2} / \mathrm{CO}$. FRP is the measure of the radiative energy released by the fire. It is usually found in the infrared part of the spectrum as this is the part of the electromagnetic (EM) spectrum that corresponds closely with the temperatures that fires occur at in the Earth system. This is because the traditional plume rise models always include wind speed and FRP in their representations, so we wanted to specifically include as many different representations of the co-emitted gases as 
well, as given in Eqs. (1)-(7), where $C$ is a constant.

$$
\begin{aligned}
H_{1} & =\alpha \cdot V_{\text {wind }}+\beta \cdot W_{\mathrm{FRP}}+\gamma \cdot[\mathrm{CO}]+\delta \cdot\left[\mathrm{NO}_{2}\right]+C \\
H_{2} & =\alpha \cdot V_{\text {wind }}+\beta \cdot W_{\mathrm{FRP}}+\gamma \cdot[\mathrm{CO}] \\
& +\varepsilon \cdot\left(\left[\mathrm{NO}_{2}\right] /[\mathrm{CO}]\right)+C \\
H_{3} & =\alpha \cdot V_{\text {wind }}+\beta \cdot W_{\mathrm{FRP}}++\delta \cdot\left[\mathrm{NO}_{2}\right] \\
& +\varepsilon \cdot\left(\left[\mathrm{NO}_{2}\right] /[\mathrm{CO}]\right)+C \\
H_{4} & =\alpha \cdot V_{\text {wind }}+\beta \cdot W_{\mathrm{FRP}}+\gamma \cdot\left[\mathrm{NO}_{2}\right]+s \\
H_{5} & =\alpha \cdot V_{\text {wind }}+\beta \cdot W_{\mathrm{FRP}}+\gamma \cdot[\mathrm{CO}]+C \\
H_{6} & =\alpha \cdot V_{\text {wind }}+\beta \cdot W_{\mathrm{FRP}}++\varepsilon \cdot\left(\left[\mathrm{NO}_{2}\right] /[\mathrm{CO}]\right)+C \\
H_{7} & =\alpha \cdot V_{\text {wind }}+\beta \cdot W_{\mathrm{FRP}}+C
\end{aligned}
$$

We calculate all of the correlation coefficients $\left(R^{2}>0.2\right)$ between the different models and the MISR measurements, ensuring that $P<0.05$. Finally, we analyze both the magnitude of the regression coefficient and the magnitude of the various best-fit terms. These models are then used to reproduce the aerosol heights and are ultimately compared with both the plume model and the actual measurements.

The seven different regression models were chosen so as to cover the entire combination of different ways to fairly and uniformly incorporate the $\mathrm{CO}$ and $\mathrm{NO}_{2}$ measurements as well as their underlying physical meanings. The seventh regression model is the approximation of the plume rise model. The fourth and fifth regression models are the approximations of the single-species linear impact of $\mathrm{NO}_{2}$ and $\mathrm{CO}$, respectively. The sixth regression model approximates the single-species nonlinear impact of $\mathrm{NO}_{2}$ and $\mathrm{CO}$ in tandem. Finally, the first through third regression models are the approximations of the combination of $\mathrm{CO}$ and $\mathrm{NO}_{2}$ in tandem with both linear (model 1) or with one linear and one nonlinear combination (models 2 and 3). This approach is consistent with and follows from some of the earlier works which try to use advanced learning to understand some higherorder, simple nonlinear forcings, still based on some physical consideration, i.e., Cohen and Prinn (2011).

\subsection{MERRA}

To obtain another independent dataset of aerosol height over the biomass burning regions, we use the NASA MERRA2 hydrophobic black carbon product (Randles et al., 2017). MERRA is a reanalysis product based on the GEOS-5 general circulation model (GCM) and meteorology suite with an output resolution of $0.5^{\circ} \times 0.625^{\circ}$ every $3 \mathrm{~h}$. The underlying aerosol model is based on GOCART aerosol, which assumes independent, non-mixed aerosols, and hence it is not an ideal environment for the high concentrations and intense mixing that occur over biomass burning regions (Petrenko et al., 2012). The assimilated aerosol fields are mostly from MODIS and AVHRR, with a small amount of input from MISR over bright surfaces and AERONET where it exists. There are however known issues with respect to MERRA and biomass burning (i.e., Buchard et al., 2015). For these reasons, we average the eight $3 \mathrm{~h}$ time periods together for each respective day of interest and use the information from $500 \mathrm{mb}$ to the surface.

\section{Discussion and results}

We approach this problem with additional measurements compared to what are normally made so that we can have a deeper insight into how these species are related to the height to which aerosols from biomass burning rise in the atmosphere. Due to the fact that there are additional processes in situ which can lead to heating, cooling and other changes to the dynamics, it is essential that we establish any first-effect relationships and then work more deeply as a community to address them in turn.

First, to enforce consistency, we impose a condition that for all days analyzed, we must have data present from all of the data sources: MISR, MODIS, MOPITT and OMI. On this basis, we explore the relationships between the two basic data sets (MISR and MODIS) and the source regions. By choosing both regression models that represent the format of the plume rise model and those that do not, but are instead based on additional information from MOPITT and OMI, we are thereby including these data in a way that is consistent with the underlying science and without bias.

Second, since these datasets make measurements with different assumptions, we will also reduce our bias in our input measurements as a function of clouds, different burning conditions, radiation feedbacks and other actual atmospheric effects. We hope that this will help us to more clearly clarify the actual atmospheric phenomena responsible for the vertical transport, for which a more conventional plume rise model may not be able to account.

Third, the range of the seven regression models is an attempt to intelligently account for the fact that the column loadings of the $\mathrm{CO}$ and $\mathrm{NO}_{2}$ offer physical meaning and insight, compared to merely being an attempt to minimize any unexplained variance. We argue that the column values of both $\mathrm{CO}$ and $\mathrm{NO}_{2}$ are both directly and indirectly related to the magnitude and the height of the vertical aerosol column. Due to the fact that the emissions of $\mathrm{NO}_{2}$ are a strong function of the fire temperature, and its short atmospheric lifetime, the $\mathrm{NO}_{2}$ is strongly related to the temperature of the fire, or the FRP, which is one of the essential driving forces of the buoyancy. This issue is strongly coupled with the fact that FRP is also one of the most error-prone of the measurements commonly used to drive the plume rise models, with the FRP commonly underestimated in the tropics due to clouds and aerosols, as given in Kaiser et al. (2012), Cohen et al. (2018), and Lin et al. (2020a). Additionally, the amount of $\mathrm{CO}$ produced is a function of the total amount of biomass burned as well as the wetness of the surface itself where the burning occurred, and hence the $\mathrm{CO}$ column loading is also 
physically related to the properties of the fires. In fact, using a measure of the $\mathrm{CO}$ column can help us to overcome the physical constraints that current measurements have in terms of addressing the issues of how much peat or understory has burned or determined whether such fires which occur without direct line of sight from above can even be detected by the current fire detection processes at all (Leung et al., 2007; Ichoku et al., 2008). The combination of high $\mathrm{NO}_{2}$ (which is produced more at higher temperature) and low $\mathrm{CO}$ (which is produced more at higher temperature) means that the ratio of $\mathrm{NO}_{2}$ to $\mathrm{CO}$ also provides further physical insight into the nonlinearities associated with the fire temperature, wetness and possibility of other heat sources and sinks at the fire-atmosphere interface such as smoldering, conversion to latent heat, etc.

\subsection{Characteristics of MISR, OMI and MOPITT species}

We use a probability density function (PDF) analysis to look at the distribution of the daily fire-constrained aggregated measurements from MISR from each region over the entire dataset from 2008 to 2011 in Fig. 2. The statistical mean and standard deviation over each region are given in Table S1. We determine that the height of measurements ranges from 0 to $29 \mathrm{~km}$ (with extremely high values in the middle stratosphere possibly being an error), which not only is higher than previous studies (Cohen et al., 2018; Val Martin et al., 2018), but also includes some extreme events which have made their way into the stratosphere. Due to the fact that, first, the majority of the plumes are injected into the boundary layer or the lower free troposphere; second, this paper is not looking into the underlying physics of stratospheric injection (Yu et al., 2019); and, third, plumes tend to accumulate within layers of relative atmospheric stability; therefore an upperbound cutoff on the measured values of $5000 \mathrm{~m}$ is imposed. This is consistent with the fact that over the regions of interest in this work, fewer than $0.48 \%$ of the total plume heights are more than $5 \mathrm{~km}$.

There are very different distributions of the measured heights over the different regions (Fig. 2). The corresponding mean, standard deviation and skewness of the heights over each respective region are given in Table S1. The average percentage of the data which have a measured height above $2 \mathrm{~km}$ (selected because it is always in the free troposphere) is $15.0 \%$, with the lowest in central Canada of $41.7 \%$ and the highest in midwestern Africa of $0.8 \%$. In terms of the amount of data measured with a height more than $4 \mathrm{~km}$, the average over the globe is $1.5 \%$, while the range is as high as $6.6 \%$ in central Canada and as low as $0.1 \%$ in midwestern Africa and northern Australia. On the other end of the comparison, some regions are very polluted near the surface, while others show the vast majority of their heights are elevated off the ground. To safely consider those plumes which are definitively near the surface (i.e., never above the bound- ary layer), a plume height below $200 \mathrm{~m}$ would roughly correspond to the boundary layer maximum in the middle of the day (Guo et al., 2019). However, due to the measurement uncertainty of the MISR heights being between 250 and $500 \mathrm{~m}$, instead the percentage of total plumes with a height below $500 \mathrm{~m}$ is chosen, which is found to have a total percentage of respective plume heights of $11 \%$ (global) and a range from a minimum of $0.68 \%$ in southern Africa to $49 \%$ in Argentina. Given the diversity of these results, there is a need to more deeply understand the driving factors across all of these different regions, as well as the importance of biomass burning in terms of transporting aerosols through the boundary layer.

Second, we perform a comparison across the different daily time series of measured aerosol heights, CO column and $\mathrm{NO}_{2}$ column as aggregated from 1 January 2008 to 30 June 2011 over all of the biomass burning regions (Fig. S1). We consider the burning season to be when we observe aerosol plumes and a peak in at least one of the $\mathrm{CO}$ and/or $\mathrm{NO}_{2}$ column measurements. Furthermore, MISR has a relatively narrow swath, not providing daily coverage to all points, coupled with a morning overpass time which may lead to negative bias in some regions and positive bias in other regions in terms of observed fires. This combination allows us to clearly demonstrate that the observed smoke peaks are in fact due to burning of a significant amount of material and are true cases of biomass burning, while not possibly being fully representative of all biomass burning events. In the observed cases, the peak occurs from November to March in central Africa and midwestern Africa; June to September in central Canada, eastern Europe and South America; April to July in central Siberia; May to December in southern Africa and northern Australia; January to April in northern Southeast Asia; March to September in Siberia and north China; and April to September in west Siberia. In addition, the length of the peak burning time is also an important consideration which varies greatly across the different regions. The length of the total number of burning days from the 3.5 years of data is an average of $108 \mathrm{~d}$, with a minimum of $14 \mathrm{~d}$ in eastern Siberia and a maximum of $388 \mathrm{~d}$ in southern Africa.

Next, we look at the impact of FRP measurements and buoyancy in terms of the plume height distribution. In general, the higher the FRP, the higher the plumes should rise. However, these measurements seem to include a larger number of total measurements in the lower free troposphere than previous plume rise model studies have been able to account for. From our measurements, we notice that the FRP (as computed on average over $1.1 \mathrm{~km} \times 1.1 \mathrm{~km}$ grids where a fire exists) has a global mean of $37.7 \mathrm{~W} \mathrm{~m}^{-2}$ and a reginal minimum and maximum of $31.1 \mathrm{~W} \mathrm{~m}^{-2}$ (Siberia and north China) and $82.6 \mathrm{~W} \mathrm{~m}^{-2}$ (central Canada) during the respective biomass burning seasons. Analyzing the extremes of the FRP leads to a top $5 \%$ of measured FRP of $132 \mathrm{~W} \mathrm{~m}^{-2}$ and a bottom $5 \%$ of measured FRP of $8.5 \mathrm{~W} \mathrm{~m}^{-2}$. Based on previous work, we would expect a general plume rise model to 

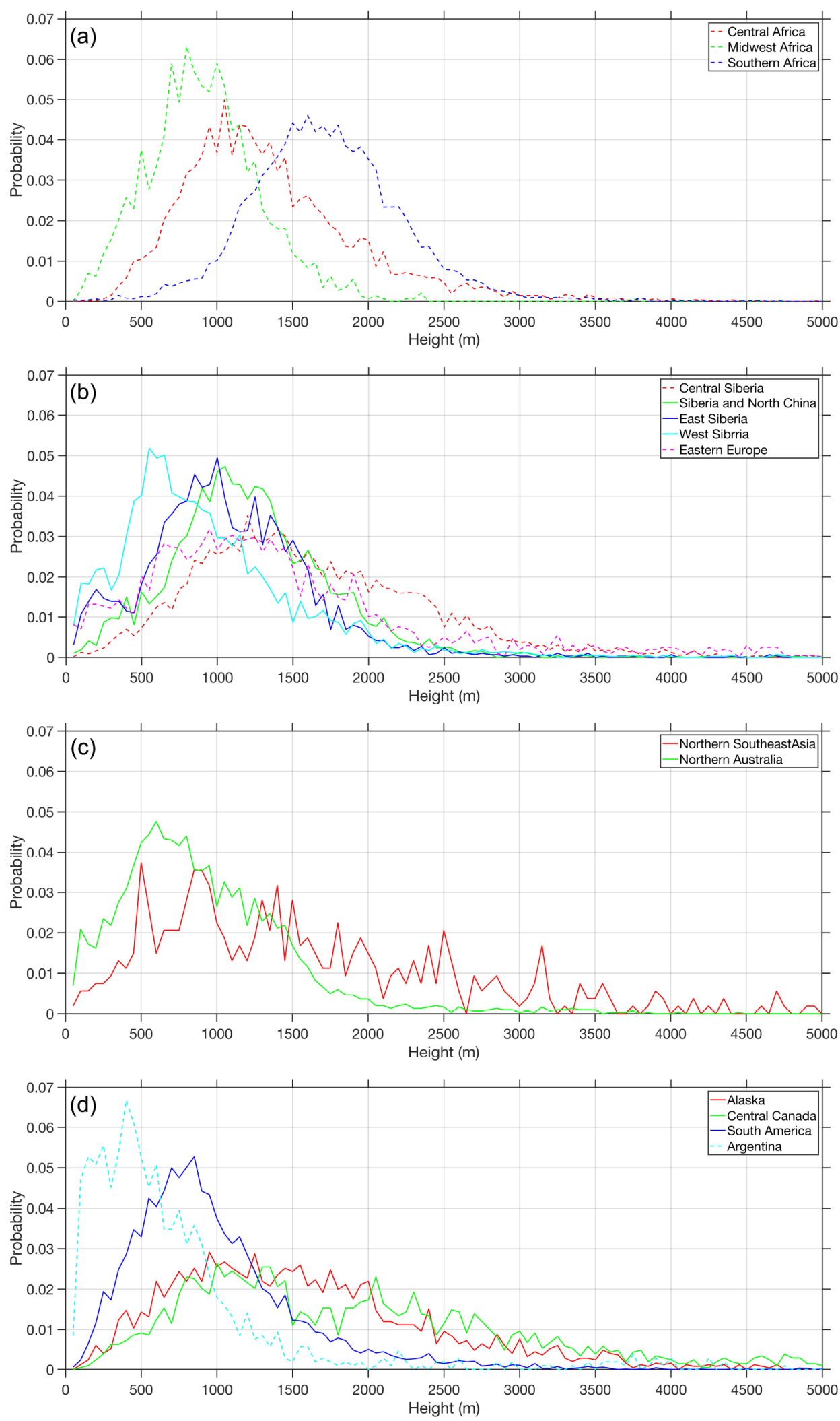

Figure 2. PDFs of all daily MISR plume height measurements from January 2008 through June 2011 (which are $5000 \mathrm{~m}$ or less) over each of the following geographic regions: (a) Africa, (b) Eurasian high latitudes, (c) tropical Asia and (d) the Americas. Solid lines correspond to regions which have a successful regression model, while dashed lines are regions which do not. 
not be able to match the observed heights well under these conditions, since the observed FRP is too low (Cohen et al., 2018; Gonzalez-Alonso et al., 2019). The high end of the FRP range of the observations in this work is not considered to be very hot in terms of fires, which should in theory help to reduce the known plume rise model bias of underpredicting very strong FRP conditions, leading to an overall improvement in the plume rise model as analyzed in this work, compared to when it is less constrained. As expected, there are more plumes found above the boundary layer in the measurements corresponding to very high FRP values than in the case of very low FRP values, although more importantly, there are still plumes found over the boundary layer in both cases, which is not expected based solely on the plume rise model formulation. One possible explanation for this phenomenon is that the biomass burning occurring during the times of year where there is a negligible impact on the atmospheric loadings of $\mathrm{NO}_{2}$ and/or $\mathrm{CO}$ is significantly more energetic and therefore has a very different height profile, compared to the times when the most emissions of $\mathrm{NO}_{2}$ and/or $\mathrm{CO}$ are produced. Another explanation is that there is additional forcing which also plays a role in terms of the aerosol plume height rise that is independent of the FRP. Yet another possibility (Mims et al., 2010; Val Martin et al., 2018) is related to there being some type of problem with the presentation of the nature of the land surface itself, since fires occurring in heavily forested and agricultural areas are likely to have significantly different vertical distributions. On top of this, there may be partially filled pixels in the remotely sensed measurements (Kahn et al., 2007; Val Martin et al., 2012). Finally, it is possible that the intense aerosol loadings themselves lead to absorption of a significant amount of the IR radiation which is in turn biassing the FRP measurements too low (Cohen et al., 2017, 2018).

It is also possible that there are significant differences to be found in the nonlinearity between FRP and the wind speed. Interestingly, if the horizontal wind speed is quite high when the air passes over the fire source, it will cause turbulence and vortices, resulting in a lifting force. On the other hand, if the wind speed is too high, it will bend the plume's momentum and reduce the upward transference based on any initial vertical injection velocity. Furthermore, the wind speed may have different relationships with convection, which itself plays a dominant role in the rise of the plume. Given these effects, we do not directly consider wind speed and the plume rise height independently, only within the confines of the plume rise model.

Since there are many underlying direct and indirect theoretical, physical and chemical connections between the loadings of the $\mathrm{CO}$ and $\mathrm{NO}_{2}$ and the overall plume heights from MISR, we want to investigate this possibility more deeply. To make this comparison, we first looked at the entire time series, not only those periods during which the measured aerosol heights obviously had an impact on the atmospheric loadings of the $\mathrm{CO}$ and $\mathrm{NO}_{2}$. Next, we selected days which had data from all three measurement sources: MISR, MOPITT and OMI. Furthermore, since we could not find such a paper in the literature, we have decided to keep the relationship open and simple, without worry of over-constraining any relationship found. In theory, the injection height of the aerosol plume is related to the emission of smoke in the wildfires, since this is a function of the amount of heat released. Therefore, we would expect that higher emissions of $\mathrm{CO}$ and $\mathrm{NO}_{2}$ should correspond to higher heights of aerosols. However, the formation mechanisms of these two trace gases is different, with $\mathrm{CO}$ being a function of oxygen availability (and possibly surface wetness), while $\mathrm{NO}_{2}$ is a function of the temperature of the burning. Furthermore, very high coemitted levels of aerosols with the very high levels of trace gases could also lead to a change in the vertical profile of the heating (Freitas et al., 2007).

To ensure that the variables are relatively independent, our analysis only considers three mixtures of these species: the independent concentrations of $\mathrm{CO}$ and $\mathrm{NO}_{2}$ and the ratio of $\mathrm{NO}_{2} / \mathrm{CO}$. We then investigate how changes in the loadings of $\mathrm{NO}_{2}, \mathrm{CO}$ and the ratio of $\mathrm{NO}_{2} / \mathrm{CO}$ are associated with changes in the height of the plume. Furthermore, we need to consider the more extreme conditions in addition to the means, and we are particularly interested in seeing how well loadings of the $\mathrm{CO}$ and $\mathrm{NO}_{2}$ can be used to model those conditions where the plume heights are extreme.

In all of the regions of the world, with the exception of the case of $\mathrm{NO}_{2}$ over Siberia and north China, we have a case where the mean value of the $\mathrm{CO}$ and $\mathrm{NO}_{2}$ measurements is higher over the set of points where the actual FRP measurements were made than over the region as a whole (Table 1). This is the point of this work, since we want to focus on the measured values from MOPITT and OMI which correspond to the same spatial locations as the measured FRP. This makes sense, since the magnitude of emissions from fires is very large compared with the non-burning season and/or surrounding areas. However, the differences in the $\mathrm{CO}$ are in general smaller than for $\mathrm{NO}_{2}$, which is further consistent with the fact that the lifetime of $\mathrm{CO}$ is much longer than that of $\mathrm{NO}_{2}$. Thankfully the case is well understood over Siberia and north China because there are some known significant urban areas close to the burning regions. Furthermore, this exception occurs in winter, where we know there is a significant enhancement of $\mathrm{NO}_{2}$ emissions due to the increase in urban biomass burning to offset the brutally cold winter conditions.

Over these fire-constrained points, we find that the variability of both $\mathrm{CO}$ and $\mathrm{NO}_{2}$ remains very low when computed on a point-by-point basis. On the other hand, over the entire region, the variability of the point-by-point measurements of both $\mathrm{NO}_{2}$ and $\mathrm{CO}$ is much higher. This is in large part due to the rapid changes in different land-use types in different parts of the regions of interest being studied (consistent with Cohen et al., 2018). These results are based on the statistics of more than 67000 daily MISR measurements. 
Table 1. Statistical summary of measured column loadings of $\mathrm{OMI} \mathrm{NO}_{2}\left(\right.$ molecule $\mathrm{cm}^{-2}$ ) and MOPITT CO (molecule $\mathrm{cm}^{-2}$ ) averaged from January 2008 to June 2011, over each entire boxed region (entire box) as well as the subset in space and time containing active fires (fire only).

\begin{tabular}{lcccc}
\hline & $\begin{array}{c}C_{\mathrm{NO}_{2}} \\
(\text { entire box })\end{array}$ & $\begin{array}{c}C_{\mathrm{NO}_{2}} \\
\text { (fire only) }\end{array}$ & $\begin{array}{c}C_{\mathrm{CO}} \\
(\text { entire box })\end{array}$ & $\begin{array}{c}C_{\mathrm{CO}} \\
\text { (fire only) }\end{array}$ \\
\hline Central Africa & $1.36 \times 10^{15}$ & $3.24 \times 10^{15}$ & $2.24 \times 10^{18}$ & $2.49 \times 10^{18}$ \\
Midwestern Africa & $1.20 \times 10^{15}$ & $3.12 \times 10^{15}$ & $2.45 \times 10^{18}$ & $2.60 \times 10^{18}$ \\
Southern Africa & $1.40 \times 10^{15}$ & $3.60 \times 10^{15}$ & $1.94 \times 10^{18}$ & $2.24 \times 10^{18}$ \\
Central Siberia & $8.63 \times 10^{14}$ & $1.11 \times 10^{15}$ & $2.04 \times 10^{18}$ & $2.78 \times 10^{18}$ \\
Siberia and north China & $1.36 \times 10^{15}$ & $1.13 \times 10^{15}$ & $2.31 \times 10^{18}$ & $2.90 \times 10^{18}$ \\
Eastern Siberia & $4.74 \times 10^{14}$ & $1.50 \times 10^{15}$ & $2.25 \times 10^{18}$ & $2.38 \times 10^{18}$ \\
Western Siberia & $1.21 \times 10^{15}$ & $1.70 \times 10^{15}$ & $2.20 \times 10^{18}$ & $2.52 \times 10^{18}$ \\
Northern Southeast Asia & $1.43 \times 10^{15}$ & $2.94 \times 10^{15}$ & $2.58 \times 10^{18}$ & $3.09 \times 10^{18}$ \\
Northern Australia & $7.53 \times 10^{14}$ & $1.73 \times 10^{15}$ & $1.50 \times 10^{18}$ & $1.73 \times 10^{18}$ \\
Alaska & $7.63 \times 10^{14}$ & $1.46 \times 10^{15}$ & $2.07 \times 10^{18}$ & $2.12 \times 10^{18}$ \\
Central Canada & $5.98 \times 10^{14}$ & $1.02 \times 10^{15}$ & $2.13 \times 10^{18}$ & $2.15 \times 10^{18}$ \\
South America & $1.16 \times 10^{15}$ & $6.36 \times 10^{15}$ & $1.78 \times 10^{18}$ & $3.08 \times 10^{18}$ \\
Argentina & $1.22 \times 10^{15}$ & $1.32 \times 10^{15}$ & $1.51 \times 10^{18}$ & $1.62 \times 10^{18}$ \\
Eastern Europe & $1.70 \times 10^{15}$ & $1.81 \times 10^{15}$ & $2.25 \times 10^{18}$ & $2.79 \times 10^{18}$ \\
\hline
\end{tabular}

Therefore, for the remainder of the work, we only use the data for $\mathrm{NO}_{2}$ and $\mathrm{CO}$ which are obtained at points where FRP measurements exist.

Note that the measurements and the results here are looking at the aerosol heights measured over small spatial and temporal domains. We are looking to analyze the impact of the initial plume rise and any very rapid adjustments in the atmosphere. The plume heights, both measured and modeled, are not consistent with large-scale transport due to meteorology, factors enhancing the stability of a layer or changing the chemistry within a plume. They certainly are not receptive to a Lagrangian type of modeling effort, which is supposed to be focused on the air itself and in particular air at the large scale. Therefore, the results given here are the best methods currently used to reproduce the spatial distribution of aerosol plumes produced by wildfires.

\subsection{Plume rise model applied to MISR and meteorological measurements}

The annual average global total cumulative FRP from 2008 to 2011 is $209 \mathrm{MW}$, based on more than 16000 measured MODIS fire hot spots. Overall, the measured FRP has been shown to be on the rise in recent years (Cohen et al., 2018; Freeborn et al., 2014), although there is still a fundamental and significant amount of underestimation based on the current measurement techniques (Giglio et al., 2006). The plume rise model in theory should take these FRP values and combine them with knowledge of the vertical thermal stability and the wind speed, to approximate the height to which the plume ultimately rises at equilibrium with its environment.

However, in reality, direct and semi-direct effects are not considered when using the simple plume rise model, al- though they are known to be important (Tao et al., 2012). Therefore, a different approach which attempts to take these forcings and/or the underlying aerosol loadings into account may lead to a better representation of the plume height rise, if such a model can be parameterized. Furthermore, the plume rise model relies on the atmospheric stability and therefore does not take into account rainfall, changes in fire burning, in situ chemical and physical production and removal, and the aforementioned radiative interactions between the aerosol and the atmospheric environment. This finding is consistent with evidence that the vertical plume rise and distribution of tropical convective clouds is sometimes dominated by in situ heating and turbulence even more so than the initial heat of condensation (Gunturu, 2010).

All of these shortcomings aside, the use of simple plume models is the current scientific standard approach, and therefore we will apply it here as well. This is done by first aggregating the daily statistics of the vertical aerosol height over all parts of each region of interest (Table 2). Direct comparisons are made between the modeled heights and the measured heights, and we find that 5 of the 14 regions studied in this work were shown to have a good match: west Siberia, Alaska, central Canada, Argentina and eastern Europe, where the modeled (and measured) average heights are respectively $0.79 \mathrm{~km}(0.95 \mathrm{~km}) 1.39 \mathrm{~km}(3.03 \mathrm{~km}), 1.73 \mathrm{~km}$ $(2.19 \mathrm{~km}), 0.65 \mathrm{~km}(0.25 \mathrm{~km})$ and $1.27 \mathrm{~km}(2.67 \mathrm{~km})$.

Next, we look at the difference from day to day at each of the sites which has a mean value less than or equal to $0.25 \mathrm{~km}$. Using these results, we find that the mean daily difference between the plume rise model and the MISR measurements as a whole shows a large amount of variation, with a global average of $0.44 \mathrm{~km}$, a maximum of $1.13 \mathrm{~km}$ (in west 
Table 2. Best-fit values for the various coefficients of the regression models based on Eqs. (1)-(7). NaN refers to predictors which are not associated with the given model.

\begin{tabular}{lrrrrrc}
\hline Region & $\alpha$ & $\beta$ & $\gamma$ & $\delta$ & $\varepsilon$ & $R^{2}$ \\
\hline Siberia and north China & 110 & 318 & $\mathrm{NaN}$ & 300 & -518 & 0.26 \\
East Siberia & -163 & -657 & 1480 & $\mathrm{NaN}$ & 437 & 0.41 \\
West Siberia & 241 & 196 & -221 & $\mathrm{NaN}$ & -263 & 0.22 \\
Northern Southeast Asia & 367 & 139 & 912 & $\mathrm{NaN}$ & 355 & 0.31 \\
Northern Australia & 211 & -4 & $\mathrm{NaN}$ & 1820 & -1580 & 0.24 \\
Alaska & 163 & 18 & 2674 & -892 & $\mathrm{NaN}$ & 0.37 \\
Central Canada & -232 & 334 & $\mathrm{NaN}$ & 3190 & -1970 & 0.50 \\
South America & 226 & 57 & 314 & $\mathrm{NaN}$ & 8 & 0.30 \\
\hline
\end{tabular}

Siberia) and a minimum of $0.04 \mathrm{~km}$ (in Argentina). Across all of the different regions we find that the plume rise model underestimates the plume height. Furthermore, we find that the differences between the plume rise model and MISR are not normally distributed, with higher values not being able to be reproduced under any conditions, strongly indicative of a bias, in that somehow the largest, hottest or most radiatively active fires are those not reproduced well by the plume rise model. In addition to this, we compute the RMSE (Table 3) as a way of quantifying overall how well the model and MISR match. The rms is found to be considerably larger than the difference of the means, indicating that a small number of extreme values dominate the overall results, which were found to be $0.67,0.88,1.36,0.40$ and $0.85 \mathrm{~km}$ in the respective five areas.

To more carefully determine the extent of any bias, we analyze the PDF of the model and measurement results (Fig. S2). This approach yields a clear determination that the plume rise model consistently underestimates the measured injection height, with the underestimate ranging from $6 \%$ (in Argentina) to $66 \%$ (in southern Africa), and a global average of $33 \%$. However, if we constrain ourselves to those fires occurring only in heavily forested regions, the average underestimate is reduced considerably to $11 \%$. On the other hand, if we look across Africa as a whole, we find that the underestimate is on average $52 \%$, a finding which deviates more from the measured aerosol vertical distribution than previous global studies (Val Martin et al., 2018) as well as those over Southeast Asia (which has previously been considered one of the world's worst performing regions for such plume rise models; Reid et al., 2013; Cohen et al., 2018). The only region over which the finding may not be statistically relevant is Alaska, where the difference between regression measurements is all constrained to within a $500 \mathrm{~m}$ height band, which falls into the MISR measurement uncertainty measurement range.

Furthermore, even though the plume rise model leads to a low bias compared with the measured height, it is still not ideal for very low plumes which are found near the surface. The plume rise model tends to instead uniformly over- estimate the amount of aerosol found in the upper parts of the boundary layer from 0.5 to $1.5 \mathrm{~km}$, while at the same time not providing any reliable amount of prediction for the cases where there is a considerable amount of aerosol under $0.5 \mathrm{~km}$. For example, the plume rise model is sometimes a good fit for aerosol heights under $0.5 \mathrm{~km}$ such as in west Siberia and eastern Europe (where $23.5 \%$ and $12.3 \%$ of the measurements are under $0.5 \mathrm{~km}$ and $27 \%$ and $13.6 \%$ of the plume rise model heights are under $0.5 \mathrm{~km}$, respectively). However, in other locations, the plume rise model grossly overestimates the amount under $0.5 \mathrm{~km}$ such as in central Africa and east Siberia (where $3.6 \%$ and $17.9 \%$ of the measurements are under $0.5 \mathrm{~km}$ and $20.5 \%$ and $51.0 \%$ of the plume rise model heights are under $0.5 \mathrm{~km}$, respectively). In the case of Argentina there is a slight underestimate of the $0.5 \mathrm{~km}$ heights by the plume rise model $(49.4 \%$ of measurements and $30.1 \%$ of the plume rise model heights). One of the reasons for this is that in general the plume rise model tends to underestimate the results from 1.5 to $2.5 \mathrm{~km}$, and it cannot reproduce results reliably at all above $2.5 \mathrm{~km}$. This is partly due to the effect of the FRP values being too low and possibly due to other processes occurring in situ which further lead to buoyancy and/or convection.

A few special regions of interest have been observed when comparing the plume rise results with the measurements. In southern Africa plumes cover 9763 pixels or $19 \%$ of the total research area, and therefore they are extremely representative of the overall atmospheric conditions. What is observed is that there is almost no aerosol (only $5.9 \%$ ) present close to the ground (from 0 to $1 \mathrm{~km}$ ). The vast majority of the aerosols, $92.6 \%$, are concentrated from 1 to $3 \mathrm{~km}$. Furthermore, we observe that the time series of both $\mathrm{CO}$ and $\mathrm{NO}_{2}$ loading is significantly higher than for other regions (Fig. S1). This finding is completely the opposite from the plume rise model result, which shows that most of the pollutants $(97 \%)$ are concentrated in the range of $0-1 \mathrm{~km}$, while almost none $(3 \%)$ are found from 1 to $3 \mathrm{~km}$. There are a few reasons for this finding. First of all, when both $\mathrm{CO}$ and $\mathrm{NO}_{2}$ loadings are high, the aerosol concentration and AOD will also be high, since they are co-emitted at roughly similar ra- 
Table 3. Statistics of measured MISR plume heights and standard deviations (second column, km) using all available daily data from January 2008 to June 2011, plume rise model heights and standard deviations (third column, km), RMSE between the MISR plume heights and plume rise model heights (fourth column, km), regression model heights and standard deviations (fifth column, km), RMSE between the MISR plume heights and regression model heights (sixth column, km), MERRA daily mean hydrophobic black carbon heights and standard deviations (seventh column, km) and finally the RMSE between the MISR plume heights and MERRA daily hydrophobic black carbon heights (eighth column, $\mathrm{km}$ ). NaN indicates that the regression model failed over the respective region. The model type with the lowest RMSE over each region is given in bold. The standard deviations are given in parentheses.

\begin{tabular}{lccclccc}
\hline & MISR data & Plume rise model & RMSE & Regression model & RMSE & MERRA data & RMSE \\
\hline Central Africa & $1.36(0.80)$ & $0.59(0.22)$ & 0.95 & NaN & NaN & $\mathbf{1 . 7 2}(\mathbf{0 . 5 0})$ & $\mathbf{0 . 5 6}$ \\
Midwestern Africa & $0.90(0.42)$ & $0.60(0.23)$ & 0.47 & NaN & NaN & $\mathbf{1 . 4 2}(\mathbf{0 . 4 5})$ & $\mathbf{0 . 4 1}$ \\
Southern Africa & $1.71(0.56)$ & $0.58(0.23)$ & 1.18 & NaN & NaN & $\mathbf{1 . 6 4}(\mathbf{0 . 5 0})$ & $\mathbf{0 . 4 4}$ \\
Central Siberia & $1.64(0.90)$ & $0.87(0.89)$ & 1.01 & NaN & NaN & $\mathbf{2 . 1 1}(\mathbf{1 . 0 1})$ & $\mathbf{0 . 6 6}$ \\
Siberia and north China & $1.27(0.97)$ & $0.80(0.64)$ & 0.69 & $\mathbf{1 . 0 7}(\mathbf{0 . 3 0})$ & $\mathbf{0 . 4 2}$ & $2.06(1.20)$ & 0.52 \\
Eastern Siberia & $1.12(1.00)$ & $0.68(0.34)$ & 0.52 & $\mathbf{1 . 3 2}(\mathbf{0 . 6 5})$ & $\mathbf{0 . 3 5}$ & $3.13(1.09)$ & 0.68 \\
West Siberia & $0.95(0.77)$ & $0.79(0.95)$ & 0.67 & $\mathbf{0 . 9 7}(\mathbf{0 . 2 9})$ & $\mathbf{0 . 4 7}$ & $1.71(0.84)$ & 0.53 \\
Northern Southeast Asia & $1.57(1.03)$ & $0.73(0.38)$ & 1.04 & $\mathbf{1 . 4 2}(\mathbf{0 . 5 1})$ & $\mathbf{0 . 6 8}$ & $1.40(0.63)$ & 0.75 \\
Northern Australia & $0.90(0.62)$ & $0.64(0.29)$ & 0.57 & $\mathbf{1 . 1 2}(\mathbf{0 . 3 8})$ & $\mathbf{0 . 5 2}$ & $1.69(0.63)$ & 0.59 \\
Alaska & $1.57(0.91)$ & $1.39(3.03)$ & 0.88 & $\mathbf{1 . 2 6}(\mathbf{0 . 4 5})$ & $\mathbf{0 . 7 7}$ & $2.48(0.97)$ & 1.01 \\
Central Canada & $1.97(1.26)$ & $1.73(2.19)$ & 1.36 & $\mathbf{2 . 1 3}(\mathbf{1 . 7 2})$ & $\mathbf{1 . 2 0}$ & $2.54(1.17)$ & 1.36 \\
South America & $0.97(0.66)$ & $0.50(0.21)$ & 0.52 & $\mathbf{0 . 9 5}(\mathbf{0 . 2 2})$ & $\mathbf{0 . 3 7}$ & $1.92(0.91)$ & 0.60 \\
Argentina & $0.69(0.70)$ & $\mathbf{0 . 6 5}(\mathbf{0 . 2 5})$ & $\mathbf{0 . 4 0}$ & $\mathrm{NaN}$ & $\mathrm{NaN}$ & $1.30(0.49)$ & 0.52 \\
Eastern Europe & $1.41(1.05)$ & $1.27(2.67)$ & 0.85 & $\mathrm{NaN}$ & $\mathrm{NaN}$ & $\mathbf{1 . 1 5}(\mathbf{0 . 5 9})$ & $\mathbf{0 . 6 5}$ \\
\hline
\end{tabular}

tios from the fires. This in turn will both lead to a further underestimation of the FRP due to the outwelling infrared, which is partially absorbed by the aerosols, and provide a further uplifting energy source due to the semi-direct effect (Tao et al., 2012; Guo et al., 2019). In other words, the assumptions underlying the plume rise model may not be completely relevant or dominant over this region under these conditions.

A second special region, which completely contrasts with southern Africa, is found in Argentina. In this region, a much smaller amount of the total research area is covered in plumes of 1063 pixels or $2.1 \%$. A large amount of the total aerosol $(83.8 \%)$ exists below $1 \mathrm{~km}$, while only a small amount $(5.1 \%)$ is found above $2 \mathrm{~km}$. In this case, the plume rise model achieved its best match globally, with a large amount $(92.2 \%)$ found below $1 \mathrm{~km}$ and a small amount $(0.35 \%)$ found above $2 \mathrm{~km}$. Furthermore, the loadings of CO and $\mathrm{NO}_{2}$ are both considerably low compared to other regions studied in this work. It is under these relatively less polluted conditions, where the fires are fewer and/or less intense, where a lower amount of total material is being burned on a per-day basis of time over the total surface area burning or where the meteorology and the vertical thermodynamic structure of the atmosphere are more uniform, that the plume rise model can achieve its best results (Table 4, Figs. 6 and S6). Thus the plume rise model is reasonable to use in such a region. However, it is still obvious that even in this best result case the plume rise model is fundamentally biased towards the aerosol vertical distribution being too low, especially the amount in the free troposphere.
As we have observed, the simple plume rise models based on Briggs (1965) are useful under specific circumstances. This is especially the case when the atmosphere is relatively stable, the total loading of pollutants is not too large (i.e., there is less fire masking and less of the semi-direct effect to contend with) and the density of fires is lower (and hence there is less overall buoyancy changing the atmosphere's dynamics). On top of this, more flat and uniform areas are less likely to have local convection, further leading to an improvement of the effectiveness of the simple plume rise model. It is for these many reasons that we find the simple plume rise model does not provide an ideal fit over many regions, and for this reason we propose a simple statistical model as an alternative.

\subsection{Regression model applied to MISR, OMI, MOPITT and meteorological measurements}

Since plume rise models rely solely on information related to fire intensity and meteorological conditions in order to compute an aerosol injection height, we want to build a relationship that also includes the net effects of pollutants as well. Therefore, we introduce and globally apply seven different combinations of relationships between FRP, wind, $\mathrm{CO}, \mathrm{NO}_{2}$ and injection height (Eqs. 1-7). Different combinations of $\mathrm{CO}$ and $\mathrm{NO}_{2}$ are applied to the linear regression model. $\mathrm{CO}$ and $\mathrm{NO}_{2}$ are independently mixed with the meteorological terms in Eqs. (4) and (5), while they are jointly mixed together with the meteorological terms in Eq. (1). A nonlinear weighted variable of $\mathrm{NO}_{2} / \mathrm{CO}$ is mixed on its own with the meteorological variables in Eq. (6), while it is mixed with 
Table 4. Statistics of the $10 \%, 30 \%$, median, $70 \%$ and $90 \%$ percentile heights $(\mathrm{km})$ of MISR heights and plume rise model heights (a) and regression model heights and MERRA heights (b). NaN refers to regions where there is no regression model result.

\begin{tabular}{|c|c|c|c|c|c|c|c|c|c|c|}
\hline (a) & $\begin{array}{l}\text { MISR } \\
10 \%\end{array}$ & $\begin{array}{l}\text { MISR } \\
30 \%\end{array}$ & $\begin{array}{l}\text { MISR } \\
50 \%\end{array}$ & $\begin{array}{l}\text { MISR } \\
70 \%\end{array}$ & $\begin{array}{l}\text { MISR } \\
90 \%\end{array}$ & $\begin{array}{c}\text { PRM } \\
10 \%\end{array}$ & $\begin{array}{c}\text { PRM } \\
30 \%\end{array}$ & $\begin{array}{c}\text { PRM } \\
50 \%\end{array}$ & $\begin{array}{l}\text { PRM } \\
70 \%\end{array}$ & $\begin{array}{l}\text { PRM } \\
90 \%\end{array}$ \\
\hline Central Africa & 0.70 & 0.99 & 1.22 & 1.53 & 2.10 & 0.33 & 0.47 & 0.57 & 0.68 & 0.85 \\
\hline Southern Africa & 1.12 & 1.44 & 1.67 & 1.92 & 2.31 & 0.32 & 0.46 & 0.56 & 0.67 & 0.84 \\
\hline Central Siberia & 0.75 & 1.15 & 1.48 & 1.93 & 2.62 & 0.38 & 0.59 & 0.74 & 0.91 & 1.27 \\
\hline Siberia and north China & 0.58 & 0.92 & 1.15 & 1.41 & 1.88 & 0.38 & 0.55 & 0.68 & 0.84 & 1.24 \\
\hline Northern Southeast Asia & 0.48 & 0.87 & 1.35 & 1.91 & 3.03 & 0.32 & 0.55 & 0.71 & 0.84 & 1.10 \\
\hline Northern Australia & 0.28 & 0.56 & 0.79 & 1.09 & 1.52 & 0.34 & 0.49 & 0.63 & 0.75 & 0.93 \\
\hline Alaska & 0.59 & 1.02 & 1.43 & 1.88 & 2.78 & 0.52 & 0.83 & 1.00 & 1.20 & 1.56 \\
\hline Central Canada & 0.72 & 1.16 & 1.73 & 2.36 & 3.51 & 0.51 & 0.74 & 0.98 & 1.68 & 3.04 \\
\hline South America & 0.38 & 0.64 & 0.85 & 1.11 & 1.65 & 0.26 & 0.39 & 0.50 & 0.60 & 0.77 \\
\hline (b) & $10 \%$ & $30 \%$ & $50 \%$ & $70 \%$ & $90 \%$ & $10 \%$ & $30 \%$ & $50 \%$ & $70 \%$ & $90 \%$ \\
\hline Central Africa & $\mathrm{NaN}$ & $\mathrm{NaN}$ & $\mathrm{NaN}$ & $\mathrm{NaN}$ & $\mathrm{NaN}$ & 1.08 & 1.47 & 1.71 & 1.96 & 2.33 \\
\hline Midwestern Africa & $\mathrm{NaN}$ & $\mathrm{NaN}$ & $\mathrm{NaN}$ & $\mathrm{NaN}$ & $\mathrm{NaN}$ & 0.87 & 1.18 & 1.40 & 1.62 & 1.99 \\
\hline Southern Africa & $\mathrm{NaN}$ & $\mathrm{NaN}$ & $\mathrm{NaN}$ & $\mathrm{NaN}$ & $\mathrm{NaN}$ & 1.01 & 1.35 & 1.62 & 1.90 & 2.29 \\
\hline Central Siberia & $\mathrm{NaN}$ & $\mathrm{NaN}$ & $\mathrm{NaN}$ & $\mathrm{NaN}$ & $\mathrm{NaN}$ & 0.87 & 1.51 & 1.99 & 2.53 & 3.49 \\
\hline Siberia and north China & 0.89 & 1.02 & 1.13 & 1.27 & 1.50 & 0.55 & 1.27 & 1.92 & 2.64 & 3.74 \\
\hline East Siberia & 0.95 & 1.41 & 1.66 & 1.88 & 2.66 & 1.72 & 2.57 & 3.14 & 3.72 & 4.56 \\
\hline West Siberia & 0.72 & 0.84 & 0.93 & 1.03 & 1.22 & 0.67 & 1.22 & 1.63 & 2.06 & 2.81 \\
\hline Northern Southeast Asia & 0.81 & 1.00 & 1.20 & 1.69 & 2.64 & 0.68 & 0.99 & 1.29 & 1.65 & 2.29 \\
\hline Northern Australia & 0.71 & 0.87 & 1.04 & 1.25 & 1.53 & 0.91 & 1.29 & 1.64 & 2.01 & 2.52 \\
\hline Alaska & 0.30 & 0.80 & 0.82 & 0.85 & 1.35 & 1.25 & 1.94 & 2.43 & 2.94 & 3.76 \\
\hline
\end{tabular}

either one of $\mathrm{CO}$ and $\mathrm{NO}_{2}$ in Eqs. (2) and (3). The reason for this is that there is a significant physical relevance for determining how much $\mathrm{NO}_{2}$ is emitted per unit of $\mathrm{CO}$, which is a strong function of the fire temperature as well as oxygen availability. This set of models is capable of providing a clear relationship between the response of either or both of $\mathrm{CO}$ and $\mathrm{NO}_{2}$. Such an approach allows for us to examine the strengths and weaknesses of each combination in terms of the spatial-temporal distribution of the measured heights, as well as the contribution to the absolute magnitude.

The regression model solely containing $\mathrm{NO}_{2}$ is an approximation of the concept that the heat of the biomass burning should have an important role to play in terms of the plume height. Furthermore, using $\mathrm{NO}_{2}$ in this way helps to get around the inherent underestimation of FRP. The regression model solely containing the $\mathrm{CO}$ is a proxy for the concept that the mass of biomass burned should make an important contribution towards the plume height. Inclusion of the
$\mathrm{CO}$ term is also a way to get around the underapproximation of the total burned area or of any significant contribution from underground burning.

The average statistical error and average statistical correlation (coefficient of determination, $R^{2}$ ) between the datasets used to determine the best-fit coefficients for $\alpha, \beta, \gamma, \delta$ and $\varepsilon$ are displayed in Table 2. While a comparison of the time series of the region-averaged injection height was made over all 14 regions, only those regions passing a level of quality control as described below are retained. First, different linear combinations are evaluated for their correlation against the MISR measurements, with an optimal combination selected and considered to be a success only if $R^{2}>0.2$ and the $P<0.05$. Furthermore, we compare the modeled average injection height in an absolute sense to the measured values, and we retain the data if the difference is smaller than $0.25 \mathrm{~km}$. Based on these results, the best-fit model-predicted 
injection height and the measured averaged injection height were found to be reasonable only at eight different sites.

In general, when $\mathrm{CO}$ or $\mathrm{NO}_{2}$ or both are included in these different combinations for these regions, the normalized coefficients of $\mathrm{CO}$ and $\mathrm{NO}_{2}$ have a larger value than the respective normalized coefficients of FRP or wind speed. This means that when these variables occur simultaneously, the contaminants have a stronger influence on the final injection height of the plume. This is found to especially be the case in regions which have higher loadings of pollution. The regression model with the nonlinear combination of the two is a proxy for the argument that it is the ratio of the heat to the total biomass burned that is an essential physical consideration to take into effect. Furthermore, this final case provides some weight to the concept that a small change in the vertical column concentration may have a stronger-than-linear effect, as is evidenced by Ichoku et al. (2008) and Zhu et al. (2018), such as in terms of absorbing aerosols in the vertical column altering the ultimate vertical distribution.

This comparison is also found to be valid in regions which in general are less polluted. For example, even in relatively clean central Canada, the linear combination of $\mathrm{NO}_{2}$ and the ratio of $\mathrm{NO}_{2}$ and $\mathrm{CO}$ produce the best fit, with the coefficient of $\mathrm{NO}_{2}$ being roughly an order of magnitude larger (at $3.2 \times$ $10^{3}$ ) compared to the coefficients of FRP and wind (which are respectively a magnitude of order smaller, at $3.3 \times 10^{2}$ and $-2.3 \times 10^{2}$ ).

Due to the fact that $\mathrm{NO}_{2}$ and $\mathrm{CO}$ have very different lifetimes in the atmosphere, a fire-based source is expected to have a high level of both $\mathrm{CO}$ and $\mathrm{NO}_{2}$ close to its source, which decays as one heads away in space from the source. This decay should be a function of the wind direction as well, as both the $\mathrm{CO}$ and $\mathrm{NO}_{2}$ upwind will not have a significant source, but downwind the $\mathrm{CO}$ will have a significant source, as shown in Fig. 5. We find that our results are consistent with this theory. First, we have found that the regions that have the highest $\mathrm{NO}_{2}$ at the same time as the MISR measurements are made also have a very strong overlap with the locations of the MISR plume heights. We further determine this to be true for every year on a year-by-year basis (Fig. S1). Second, we find that the higher values of $\mathrm{CO}$ match well with the year-to-year locations of MISR fires (or downwind thereof) at most of the sites, including in Alaska, central Canada, central Siberia, eastern Europe, east Siberia, northern Southeast Asia, Siberia and north China, and South America. As expected, there is greater smearing away from the source regions. As expected, this is due to the fact that the lifetime of $\mathrm{CO}$ is much greater.

Following these ideas, the idea of characterizing the aerosol height using the ratio of $\mathrm{NO}_{2} / \mathrm{CO}$ is found to nicely separate the data into three different groups, based on the bands generated by the central $80 \%$ of each respective region's $\mathrm{NO}_{2} / \mathrm{CO}$ PDF. Group 1 consisting of Siberia and north China and central Canada has a $\mathrm{NO}_{2} / \mathrm{CO}$ range from $1 \times 10^{-4}$ to $9 \times 10^{-4}$. Group 2 consisting of the remaining regions has a $\mathrm{NO}_{2} / \mathrm{CO}$ range from $2 \times 10^{-4}$ to $15 \times 10^{-4}$ to $20 \times 10^{-4}$. Group 3 consisting of South America has a $\mathrm{NO}_{2} / \mathrm{CO}$ range from $6 \times 10^{-4}$ to $43 \times 10^{-4}$. This strong differentiation is consistent with the ratio of $\mathrm{NO}_{2} / \mathrm{CO}$ representing a physical meaning but is a single, continuous variable connected with the temperature of the burning, the wetness of the burning material, the latent heat flux, and the type and amount of biomass being burned.

Furthermore, in terms of changes in time, a climatology of $\mathrm{CO}$ should be slightly higher due to the added emissions from the fires, but the $\mathrm{NO}_{2}$ should be much larger than the climatology, since there is little to no retention in the air, as demonstrated in Table 1. To account for this, we have also looked at the difference between the fire times and the longterm climatology. Over regions which are urban and hence contribute randomly to the variance, we expect the differences to be smaller than due to the fires, and this is observed clearly as well. On top of this, the $\mathrm{NO}_{2}$ column loading and the ratio of the $\mathrm{NO}_{2} / \mathrm{CO}$ column measurements over only the selected grids which have available FRP measurements and over the larger regions as given in Fig. 5 are found to generally be consistent, with the ratio found to be more so (Table $\mathrm{S} 2$ ). This indicates the $\mathrm{NO}_{2} / \mathrm{CO}$ column ratio over the fire regions tends to be consistent with the fire plumes as a whole and is not found to be significantly influenced by urban sources of $\mathrm{NO}_{2}$, which would lead to a vastly faster chemical titration of $\mathrm{NO}_{2}$ compared to $\mathrm{CO}$. All of these results are also shown to be consistent with recent work (Cohen, 2014; Lin et al., 2014, 2020a), showing that the characteristics of the spatial-temporal variability of fires are quite different from those of urban areas and have a much higher variability both week to week and interannually.

\subsection{Comparison between the plume rise model and the regression model}

The results in Table 3 indicate that inclusion of either $\mathrm{CO}$ or $\mathrm{NO}_{2}$ or in some cases both always provides a better fit to the measured vertical heights when using the regression aerosol height rise model, compared with those model cases where the loadings of the gases are excluded. In addition, the fit is better over a larger number of regions (eight regions versus five regions); details are shown in Fig. S3. What we observe is that the regression model does relatively better in regions which are more polluted, while the plume rise model does relatively better only in regions which have very low amounts of burning in terms of FRP. A detailed look at the day-by-day values from the MISR measurements of aerosol height, the regression model of aerosol height and the plume rise model is given in Fig. 3.

As shown in Fig. 3 there are three regions where both modeling approaches work well. In west Siberia, the regression model shows more stability than the plume rise model, with the results more narrowly concentrated around $1000 \mathrm{~m}$. Furthermore, the results are mostly found within the range of the 

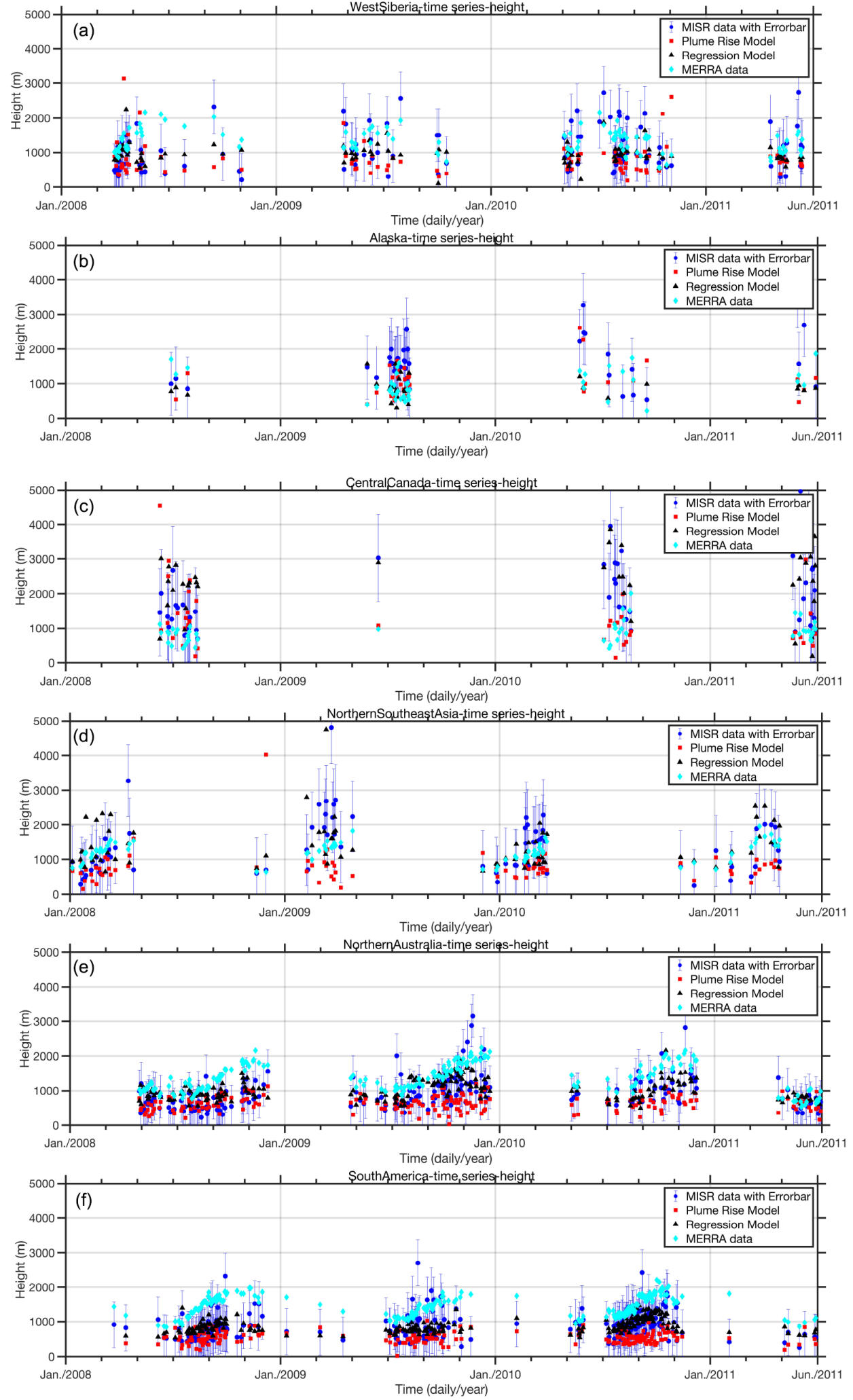

Figure 3. Time series of daily average measured MISR aerosol height (blue circles, $\mathrm{m}$ ) with an error bar corresponding to $1 \sigma$ (blue bars, $\mathrm{m}$ ), the plume rise model height (red squares, m), the regression model height (black squares, m) and the MERRA hydrophobic black carbon mean height (blue diamonds, m). Panel (a) corresponds to west Siberia, (b) to Alaska, (c) to central Canada, (d) to northern Southeast Asia, (e) to northern Australia and (f) to South America. Missing data points are due to a lack of MISR measurements and/or measurements of regression model predictor(s). 
measured variation. The plume rise model results are also relatively stable, although more dispersed in general than the regression model results. Overall the rms is 0.47 between the measured values and the regression model, while it is $0.67 \mathrm{~km}$ between the measured values and the plume rise model. A similar set of results is found in Alaska, with the rms for the regression modeling being $0.88 \mathrm{~km}$ and that of the plume rise model being $0.77 \mathrm{~km}$. The major difference here is that the plume rise model results have a variance higher than that of the measurements (SD of $0.91 \mathrm{~km}$ for the regression model and $3.03 \mathrm{~km}$ for the plume rise model). In the case of central Canada, although both modeling approaches have a decent fit, there is a clear difference between their overall performance. In general, the results of the plume rise model $(1.73 \mathrm{~km})$ are biased significantly lower than both the measurements $(1.97 \mathrm{~km})$ and the regression model $(2.13 \mathrm{~km})$, while there is little bias between the measurements and the regression model. To make this point clear, only roughly $7.9 \%$ of the measured results are outside of 1 standard deviation from the measured mean, while $50 \%$ of the plume rise model results and $43 \%$ of the regression model results are found to be outside of the 1 standard deviation from the measured mean. Note that this is the site which has the highest RMSE and still yields a successful fit for both modeling approaches. Details are given in Fig. S4.

In some of the more highly polluted regions, the regression model showed a decent performance, while the plume rise model did not. The overall goodness of the fit of the regression model is reasonable in the cases of South America, Siberia and north China, northern Southeast Asia, and northern Australia. This is because these areas emit large amounts of $\mathrm{CO}$ and $\mathrm{NO}_{2}$, in some cases solely during the biomass burning season and in other cases due to a combination of biomass burning and urban sources. Overall in these more polluted regions, the regression model is found to have little bias (respectively $-0.02,-0.20,-0.22$ and $0.15 \mathrm{~km}$ ), which helps to establish the predictive ability of using the gas loadings in terms of predicting the vertical distribution of the aerosol heights.

Although the vertical distribution of aerosol cannot be successfully simulated at all sites by using the regression model approach, at the sites where it provides a reasonable fit, it seems to do better than the plume rise model approach. This is further found to be true in the case where the data at the high end of the $\mathrm{NO}_{2} / \mathrm{CO}$ ratio profile are considered. This improvement is found in terms of both the bias and the rms under all conditions, and even more so at the respective top and bottom $10 \%$ of each respective range of the $\mathrm{NO}_{2} / \mathrm{CO}$ ratio, in which the subset of regression model heights performs much better than the respective plume rise model heights when compared with the MISR height distribution (Fig. S7).

These findings are consistent with real true world conditions, where there is a significant impact of co-emitted aerosols and/or heat, and these results with the $\mathrm{NO}_{2} / \mathrm{CO}$ ratio would hint that higher burning temperature conditions, or fewer oxygen-limited conditions, may be important driving forces. These changes either directly alter the heating throughout the profile or indirectly introduce a negative bias on measurements of the FRP below. No matter the underlying specific reasons, overall we find that the regression model approach yields at least as good if not a more precise representation of the plume rise height compared with the simple plume rise model. However, combining the two approaches yields the best overall result, since there are some locations in which each approach is better than the other approach.

What is most important to note is that in some of the regions, none of these simple approaches work. This is particularly so when the measured distribution of the aerosol heights shows a diverse set of sources. For example, in Africa there are significant sources from biomass burning as well as from rapid urbanization and burning over many different land use types and under many different types of conditions. Another potential problem occurs when there may be a significant amount of smoke which has been transported from another region, such as the exchange of smoke between the Maritime Continent and northern Australia. Furthermore, both approaches will not tend to work well under conditions in which the atmosphere is not highly stable or has a high variation in weather conditions. Under these conditions, a more complex modeling approach and the improvement of measured fire data are necessary.

\subsection{Comparison between MISR and the three models}

A comparison between the overall performance of the plume rise model, the regression model and MERRA leads to a few conclusions (Table 3). First of all, where the regression model exists, it reproduces the MISR height better than both the plume rise model and MERRA. This includes over regions where the overall RMSE is very low such as eastern Siberia and South America as well as regions where the overall RMSE is large, such as central Canada. This is true over regions in the Arctic as well as in the tropics. Secondly, over the regions in which the regression model does not exist, MERRA provides a better reproduction of the MISR height than the plume rise model in all cases, except for over Argentina. Perhaps this is true because of the fact that although MERRA uses data assimilation and a plume rise model type of code built in, the sharp height rise of the Andes Mountains and high cloud cover over this region lead to challenges that the global MERRA model cannot handle well. The second possible explanation is that the overall height of the plume is very low over Argentina and the local meteorology and FRP values are quite similar, which play to the plume rise model's strengths.

Furthermore, comparing the performance of the plume rise model, the regression model and MERRA at different percentiles of height leads to additional conclusions (Table 4). On the one hand, the regression model is the only one which does not have an obvious bias versus MISR measurements, 
with the regression model sometimes overapproximating and other times underapproximating different geographic locations at different height levels. In fact, the results at the median and $70 \%$ height levels are an excellent fit for four of the eight different regions. On the other hand, both the plume rise model and MERRA have obvious biases. The plume rise model is almost always too low, with the only exception being its ability to model 6 of the 14 regions reasonably well at the $10 \%$ height level (i.e., the bottom of the plume). However, in the case where the $10 \%$ level is higher than other cases, such as for a very narrow distribution, the plume rise model still does a poor job. MERRA is almost always too high, with it performing best only in southern Africa and eastern Europe. Furthermore, the results from the plume rise model tend to also be narrower than the data, while the results from MERRA tend to be broader than the data. The results of MERRA being broad, as demonstrated clearly in Fig. 4, are not due to a high interannual variability, which actually barely exists in the MERRA dataset compared with the regression model and MISR, but instead due to too much aerosol being found too high in the atmosphere, as well as too much aerosol being found at the surface.

The MISR data, regardless of the region, show some amount of interannual variability. This ranges from a minimum over east Siberia and Siberia and north China, to a maximum over central Canada and northern Southeast Asia. On the other hand, MERRA shows only a very small variation anywhere, with most of the years exactly the same as each other. The amount at the surface is always much larger than found in MISR, and the amount in the middle free troposphere is also much larger than in MISR. The largest variation in MERRA is found in central Canada, Alaska and northern Australia. All of these are regions which are relatively cloud free and have a higher number of ground stations, and therefore will have a large amount of the total MERRA model contribution from reanalysis data.

In the case of east Siberia there is only burning observed by MISR in 2 of the 4 years studied here, although these two different years have quite a different distribution. In 2008, the aerosol is limited in height to under $1000 \mathrm{~m}$, while in 2010 , the aerosol has a peak height at $1000 \mathrm{~m}$ and a significant fraction up to $2000 \mathrm{~m}$. In the case of Siberia and north China, the peak ranges from 800 to $1200 \mathrm{~m}$ and the maximum ranges from 2200 to $3000 \mathrm{~m}$. MERRA shows no burning at all in east Siberia, with a completely flat profile all 4 years and a consistent burning year to year, with the aerosol all confined to $1000 \mathrm{~m}$ and below over Siberia and north China. In terms of the regression model, the fact that there is a good fit is supported by Fig. 5. As can be observed, all of the fire data points occur in regions of high $\mathrm{CO}$ and the vast majority also occur in regions of high $\mathrm{NO}_{2}$. In Siberia and north China, the findings in both of the years in Fig. 5 lend support, albeit from two different perspectives. The first is that the fires always overlap with regions of high CO and that in the 2011 one of the major differences is that the region in the middle has low $\mathrm{CO}$ and no fires, which were both present and highly polluted in 2008. The $\mathrm{NO}_{2}$ is always high over the southern region and is never very high in the central or northern regions, likely due to the intense cold air present in these regions altering the $\mathrm{NO}_{2}$ chemistry.

Over central Canada the MISR data show peaks or subpeaks at $1000 \mathrm{~m}$ in 2008,2800 and $3200 \mathrm{~m}$ in $2009,2000 \mathrm{~m}$ in 2010 , and 1000 and $2600 \mathrm{~m}$ in 2011 . In many of these years the amount located in the free troposphere is much larger than the amount in the boundary layer. Yet, even though this is the region in which MERRA has the most interannual variability, in all cases, the vast majority of the aerosol is found below $1000 \mathrm{~m}$. Furthermore, no peaks or sub-peaks are found anywhere above the surface. Finally, MERRA only shows 1 year to be considerably different from the others, whereas the MISR data show that all 4 years are quite different. By looking at Fig. 3, we can see that the regression model underestimates the plume on some days, overestimates the plume on some days and is nearly perfect on some days. There is no bias, and the fact that it is able to capture the range of values over all 4 years indicates that the performance is not only better on average but also better at capturing the interannual variation over this region. This finding is further supported by Fig. 5, where all of the MISR fire points in central Canada in 2010 are found in high-CO pixels, and most of the MISR fire points are also found in high- $\mathrm{NO}_{2}$ pixels. This demonstrates that the vast majority of the MISR plumes are local in nature and actively connected with the ground (due to the short lifetime of $\mathrm{NO}_{2}$ ), are in relatively cloud-free regions where these remotely sensed platforms will work (but not necessarily MODIS which may be blocked by the high AOD levels) and are also in regions which are clearly heavily polluted by $\mathrm{CO}$ during these times, but are not normally so.

The MISR measurements over northern Southeast Asia show the majority under $1000 \mathrm{~m}$ but a second peak around $2500 \mathrm{~m}$ in 2008 and the peak at $2500 \mathrm{~m}$ and a large amount up to $3200 \mathrm{~m}$ in 2009 . The peak was spread from 500 to $2500 \mathrm{~m}$ in 2010, and there were peaks at 1000,1200 and $2200 \mathrm{~m}$ in 2011. This huge amount of interannual variability is not at all captured by MERRA, which is consistent with other recent findings over this area of the world, demonstrating that many products based on MODIS tend to have problems (i.e., Cohen, 2014, Cohen et al., 2018). However, the regression model performs well over this region as over all of the years, with measurements again showing an unbiased representation in all 4 years of the height, with some days high, other days low and some days nearly perfect. This is in part demonstrated clearly in Figs. 3 and 5 by the fact that the MISR fire points occur over the highest loadings of $\mathrm{CO}$ and $\mathrm{NO}_{2}$ found among any region anywhere else in the world as observed in this study.

In terms of the magnitudes of the vertical temperature gradient $(\mathrm{d} T / \mathrm{d} z)$ and the vertical wind speed at the surface, we have not found any correlation or relationship between 

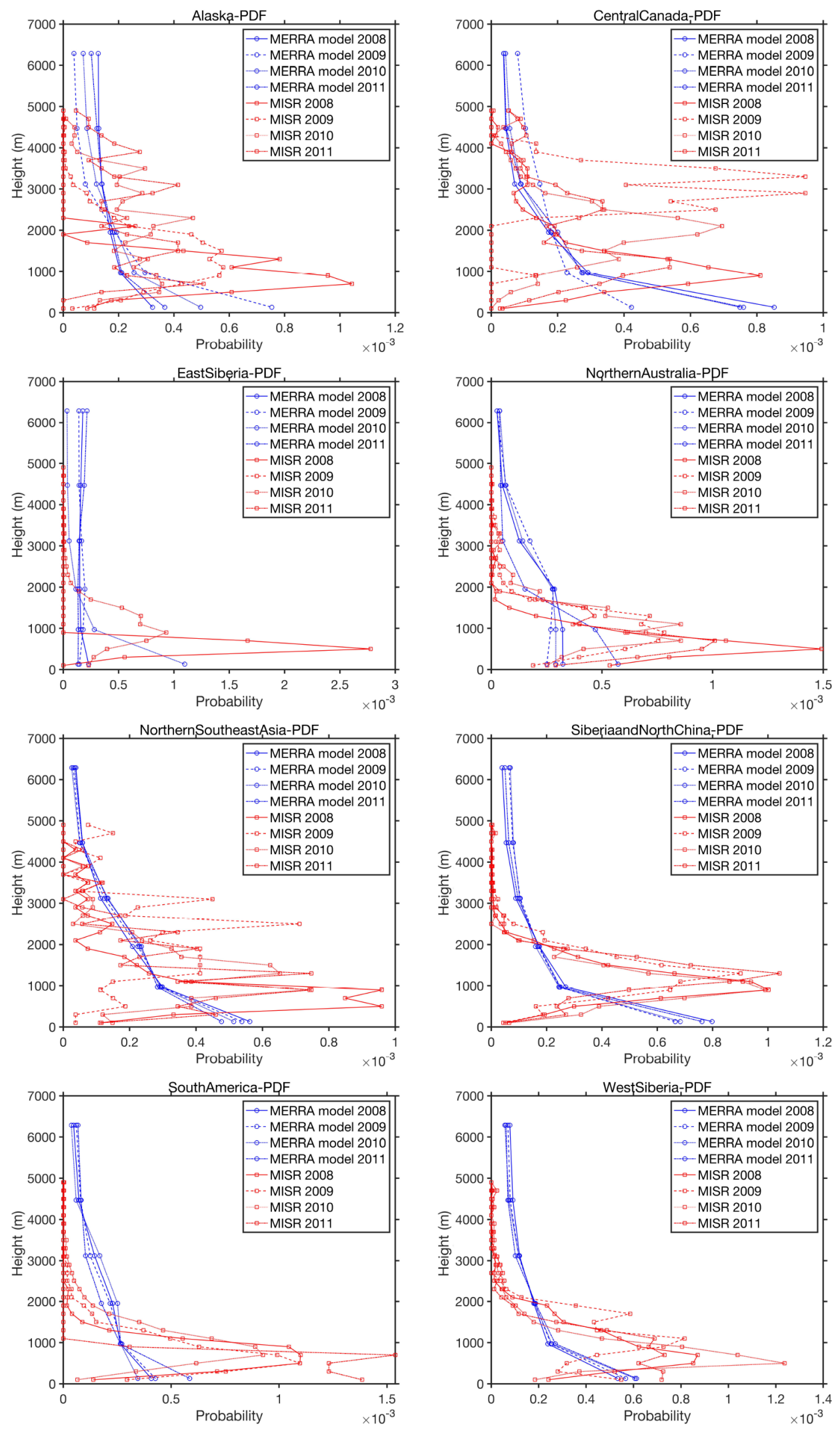

Figure 4. PDF of the vertical distribution of MISR heights (red lines for 2008, red dashes for 2009, red dots for 2010 and red dashes-dots for 2011) and MERRA hydrophobic black carbon heights (blue lines; color scheme is the same as for MISR). These plots are only over regions in which the regression model applies. 

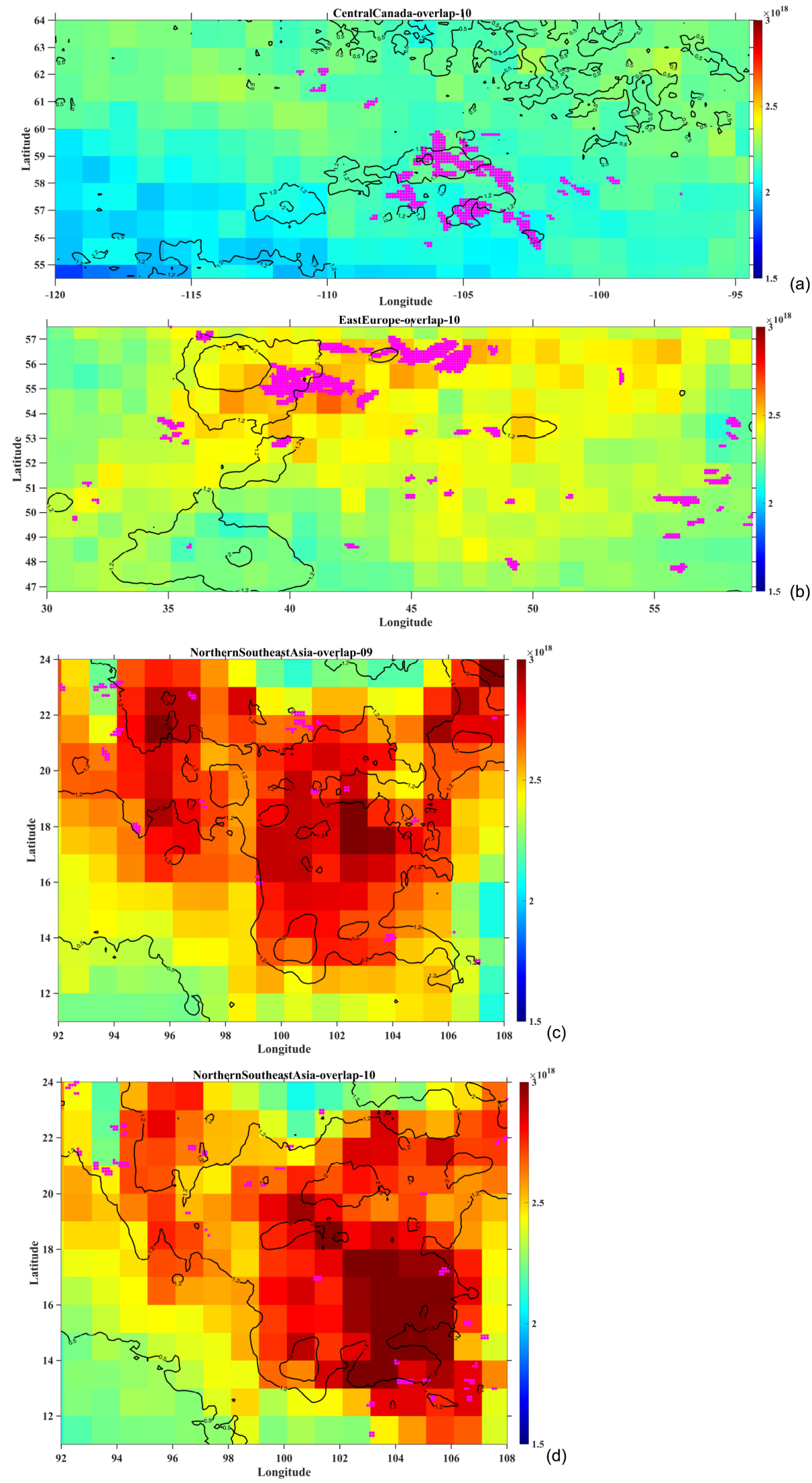

Figure 5. 

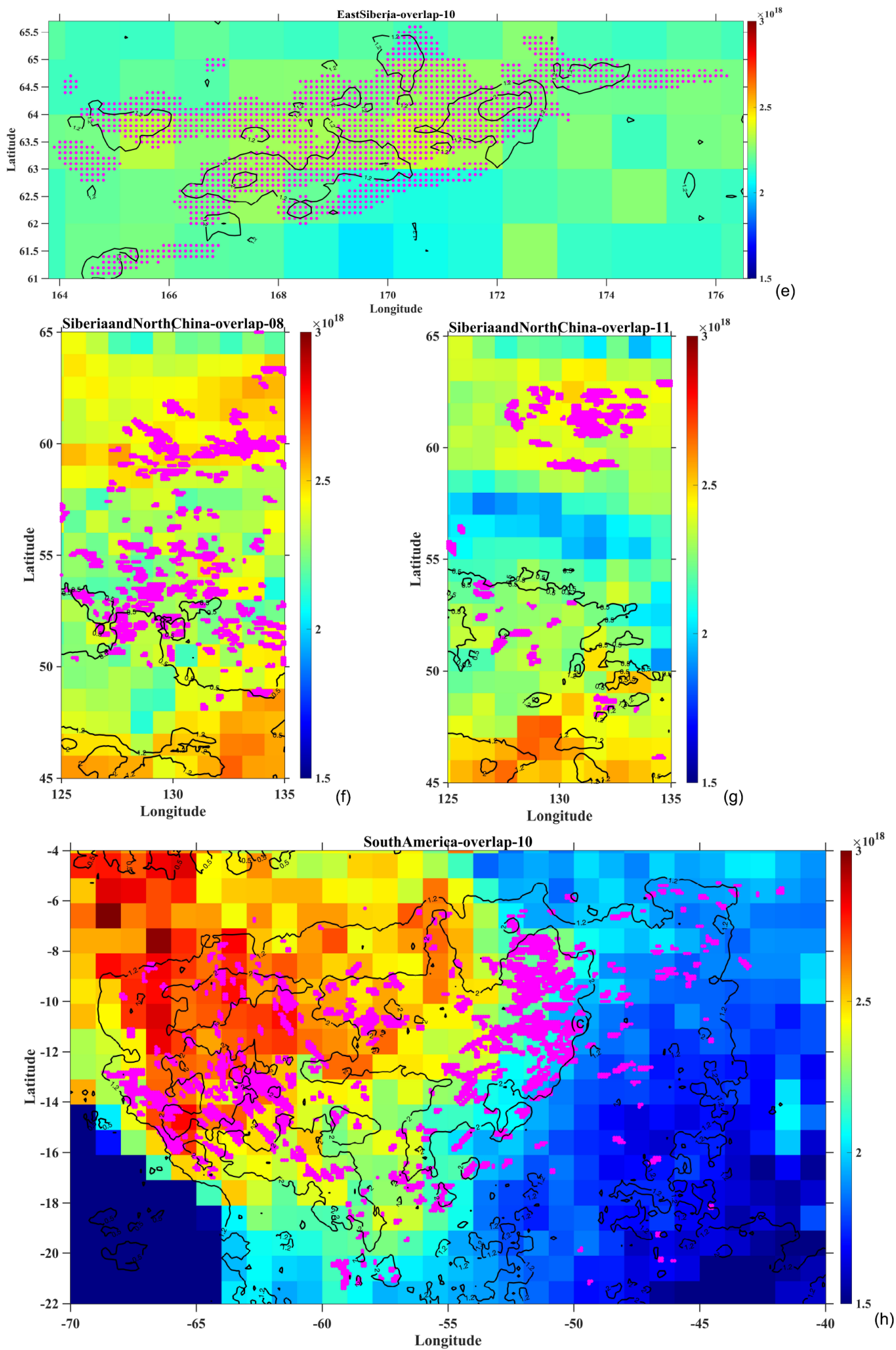

Figure 5. Spatial distribution of annual fires (magenta dots), mean $\mathrm{NO}_{2}$ column loading on days where there are fires (black isopleths, $\times 10^{15} \mathrm{~mol} \mathrm{~cm}^{-2}$ ) and mean CO column loading on days where there are fires (color bar, $\mathrm{mol} \mathrm{cm}^{-2}$ ). The corresponding regions are (a) 2010 central Canada, (b) 2010 east Europe, (c) 2009 and (d) 2010 northern Southeast Asia, (e) 2010 east Siberia, (f) 2008 and (g) 2011 Siberia and north China, and (h) 2010 South America. 
the cases in which the regression model performs better or worse. Even considering those cases in which there are extremely atypical values in these variables, such as positive temperature gradients (i.e., an unstable atmosphere) or negative temperature gradients which are more negative than the $-9.8 \mathrm{~K} \mathrm{~km}^{-1}$ pure dry-air thermodynamic limit (i.e., extreme stabilization due to intense aerosol-cloud cooling), as observed in Fig. 6, there is still no discernable relationship found between the meteorological parameters and the aerosol height. This provides a further piece of support to the idea that the regression model works well under conditions where there is some local nonlinear forcing in the system which is not being taken into account, whether it is a coupled chemical effect, an aerosol dynamical effect, an aerosol size effect, a radiative-dynamical effect, a thermodynamic effect, a direct radiative effect, a semi-direct radiative effect or an indirect radiative effect. All of these known effects have been accounted for to some degree by the loadings of $\mathrm{NO}_{2}$ and $\mathrm{CO}$, but are otherwise missed by the model underlying the meteorological reanalysis data (e.g., Cohen et al., 2011; Wang et al., 2009).

However, it does seem that under the conditions where the regression model was not able to be formed there are some important differences specifically in terms of the vertical temperature gradient variable. Specifically, in the cases in which the value of $\mathrm{d} T / \mathrm{d} z$ is either more negative than $-9 \mathrm{~K} \mathrm{~km}^{-1}$ or more positive, the MERRA results are far better than those from the plume rise model, compared to not under those conditions. However, such cases only account for $15 \%$ or fewer of the total cases observed in this study and therefore do not play an outsized role.

\section{Conclusions}

This work quantifies the measured values of the aerosol vertical distribution over biomass burning areas of the Earth on a daily basis from January 2008 through June 2011. We find that there is a significant amount of total aerosol which reaches the free troposphere as well as large amounts which are not uniformly distributed throughout the boundary layer, both of which are not readily explained by first-order theoretical approximations and present-day community-standard models.

To address these issues, we introduce a new approach, based on remotely sensed measurements of fire properties, wind and column loadings of $\mathrm{NO}_{2}$ from $\mathrm{OMI}$ and $\mathrm{CO}$ from MOPITT to constrain the aerosol heights over different geographic regions. This approach is based on the physical concept that the emissions of aerosols and the height to which they rise should be related to other co-emitted species like $\mathrm{NO}_{2}$ and $\mathrm{CO}$ and the co-emitted heat, which is also a function of the ratios of $\mathrm{NO}_{2}$ and $\mathrm{CO}$ produced by the burning. Our results are compared against both the measured MISR
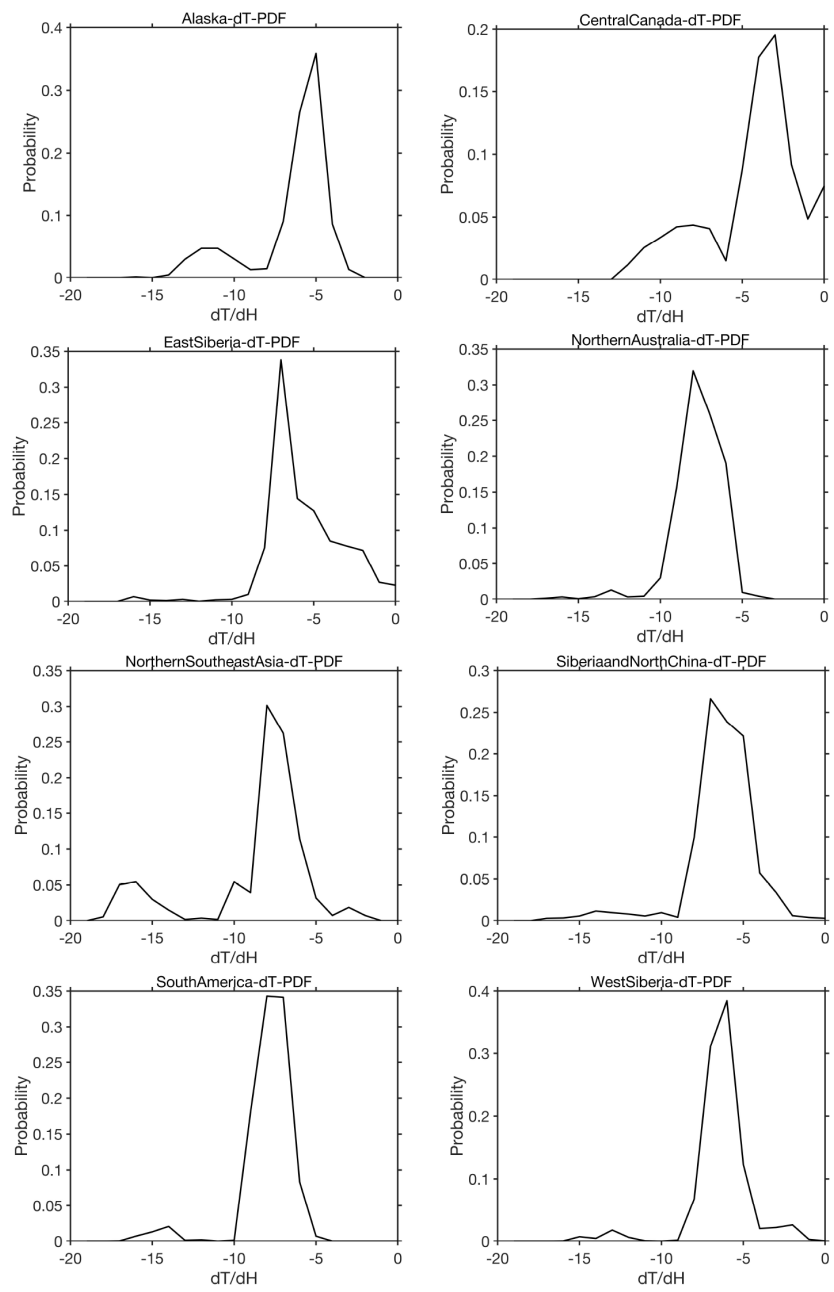

Figure 6. PDFs of the NCEP reanalysis vertical temperature gradient $\mathrm{d}[\mathrm{K}] / \mathrm{d}[\mathrm{km}]$ over the locations and days that contain MISR plumes. The eight regions over which the regression model are valid are shown.

height values and basic plume rise model computations using the same fire radiative power and meteorological datasets.

Our results indicate that our new method reproduced the measured values significantly better over much of the world in terms of reproducing the measured vertical distribution compared with the simpler plume rise approach. Specifically, we find that applying the plume rise model leads to a model underestimation of the measured MISR heights overall, whereas our approach, where it works, does not exhibit such a bias. This finding is consistent with the fact that FRP is underestimated globally, in part due to clouds and aerosols and in part due to sampling and other issues. We also find that the plume rise model tends to be too narrowly confined compared with the regression model and the modeled results. However, the plume rise model does better in terms of reproducing the aerosol injection height when it is solely contained and well mixed within the atmospheric boundary 
layer, but for higher altitudes the model capability is poor. The average underestimation of the plume rise model injection height is $33 \%$. On the other hand, the regression model has an overall improved accuracy of the measured results, in particularly doing a better job reproducing results in the free troposphere. The regression model is also more widely applicable around the globe, with the number of regions successfully simulated increasing from five to eight. As we have demonstrated, the impact of $\mathrm{NO}_{2}$ (as a proxy for the burning temperature) is always essential, and the impact of $\mathrm{CO}$ (as a proxy for the total biomass burned) is usually essential as well. We have further shown that the simplest regression model, the approximation of the plume rise model, never yields the best fit to the data.

Specifically, we find that the plume rise model works well in regions which are not frequently cloud covered during the local biomass burning seasons, in particular so over nontropical forested regions. Specifically, the plume rise model has its greatest successes in Alaska (RMSE of $0.77 \mathrm{~km}$ for the regression approach versus $0.88 \mathrm{~km}$ for the plume rise model approach), Argentina (the regression model approach does not succeed versus and RMSE of $0.40 \mathrm{~km}$ for the plume rise model approach) and western Siberia (RMSE of $0.47 \mathrm{~km}$ for the regression approach versus $0.67 \mathrm{~km}$ for the plume rise model approach). In most of the other parts of the world, the regression model approach is much better at reproducing the vertical distribution than the plume rise model, even including some major extreme events including the release of aerosols into the stratosphere, and it tends to do so with a reasonably lower RMSE and low standard deviation.

One of the major advantages of the regression model approach is that it is more capable of picking up those cases where aerosols are lofted into the lower free troposphere, and another advantage stems from its ability to better reproduce those cases where the near surface is clean but the upper part of the boundary layer is polluted. In the cases of eastern Siberia and Amazon South America, we find that the regression model performs reasonably well, while the plume rise model does not succeed. In the case of northern Australia, the regression model is capable of reproducing the aerosol height with a relatively reasonable set of statistics, although the measurements in this region are found to be very unique; sometimes the plume is mainly concentrated in the lower free troposphere and is local in nature, while other times it is found in the upper troposphere and lower stratosphere, in which case it is thought to be transported from the Maritime Continent. We also find that the regression model works well in two other special cases. The first is the case of Siberia and north China, where there is a considerably large amount of local urban pollution which is mixed into the biomass burning plumes. The second is the case of northern Southeast Asia, where there are both large amounts of local pollution and considerable issues with extensive cloud cover.

Our results clearly show that where we can successfully form a regression model it performs better than both the plume rise model and MERRA. The specific forms of the regression model that are the best are those which have $\mathrm{NO}_{2}$ or a combination of $\mathrm{NO}_{2}$ and $\mathrm{CO}$ (in particular when the nonlinear term $\mathrm{NO}_{2} / \mathrm{CO}$ is considered). These results are consistent with our hypothesis and literature review that show new forms of nonlinearity relating plume rise height to factors influencing buoyancy, radiative transfer and energy transfer in situ, and/or biases in remotely sensed measurements of FRP and land-surface products are important, even though they are not considered in the present generation of plume rise models (including the global-scale models underlying MERRA). In the cases where we cannot form a regression model, we find that MERRA performs better than the plume rise model everywhere, except for Argentina, which has a unique high mountain just upwind in the Andes, coupled with a very low overall height, all of which are disadvantages for the models underlying MERRA. In general, this shows that improved model complexity and data assimilation do produce a better result, as expected.

We propose the results as a first step of a new approach to parameterization that might help us to move forward in terms of improving our ability to reproduce heights of fire plumes for regional- and global-scale modeling and analysis studies over many different periods of time. We believe that our sample dataset is currently not sufficiently long to form an ideal fit, and hence we thought that excluding data to self-compare was not an ideal use of the very limited resources we had. We do hope that as more new datasets are released, the community will have access to more relevant input data, and as more MISR plume height data are released, the community will have more access to better understand the vertical distribution of height.

Based on these results, including over those regions where none of the results yield a satisfactory response, we have come up with a list of recommendations for how to improve the reproduction of the vertical aerosol distribution in the future. First, improve the accuracy of FRP measurements, especially so under cloud and heavily polluted conditions. Second, improve the ability of simple models to compensate for the impact of local-scale radiative forcings, deep convection, aerosol-radiation interactions and aerosol-cloud interactions. Thirdly, the finding that the $\mathrm{NO}_{2} / \mathrm{CO}$ ratio is extremely important in terms of matching the vertical distribution works to address the larger community issue of flaming versus smoldering in a more smooth and precise way, opening the possibility of a new continuum approach to consider burning wetness, temperature and heat. Based on our overall results, we believe that an improvement can be made to the current generation of GCMs, atmospheric chemical transport models and remote sensing inversions, all of which depend on a more precise knowledge of the aerosol vertical distribution. 
Code and data availability. All processed data, results and codes are freely available for download at https://doi.org/10.6084/m9.figshare.10252526.v1 (Wang and Cohen, 2019) and https://doi.org/10.6084/m9.figshare.12386135.v1 (Wang and Cohen, 2020). MISR data were obtained from https: //misr.jpl.nasa.gov/getData/accessData/ (last access: 1 September 2019, Nelson et al., 2015), MOPITT data were obtained from https://doi.org/10.5067/TERRA/MOPITT/MOP03J_L3.008 (NASA/LARC/SD/ASDC, 2000), OMI data were obtained from https://doi.org/10.5067/MEASURES/MINDS/DATA301 (Lamsal et al., 2020), NCEP data were obtained from https: //psl.noaa.gov/data/gridded/data.ncep.reanalysis.html (last access: 1 September 2019, NOAA/OAR/ESRL PSL, 1996) and MERRA data were obtained from https://doi.org/10.5067/LTVB4GPCOTK2 (GMAO, 2015).

Supplement. The supplement related to this article is available online at: https://doi.org/10.5194/acp-20-15401-2020-supplement.

Author contributions. SW was responsible for data curation, formal analysis, investigation, software, visualization, and writing the original draft. JBC was responsible for conceptualization, funding acquisition, investigation, methodology, project administration, resources, supervision, validation, writing the original draft, reviewing and editing. CL was responsible for data curation, investigation, and software. WD was responsible for software and visualization.

Competing interests. The authors declare that they have no conflict of interest.

Acknowledgements. We would like to acknowledge the PIs of the MISR, MOPITT and OMI instruments for providing the remote sensing measurements and the NCEP and MERRA2 reanalysis project for providing the meteorology and hydrophobic black carbon measurements.

Financial support. This research has been supported by the Chinese National Young Thousand Talents Program (grant no. 41180002), the Chinese National Natural Science Foundation (grant no. 41030028) and the Guangdong Provincial Young Talent Support Fund (grant no. 42150003).

Review statement. This paper was edited by Anja Schmidt and reviewed by two anonymous referees.

\section{References}

Achtemeier, G. L., Goodrick, S. A., Liu, Y., Garcia-Menendez, F., Hu. Y., and Odman, M. T.: Modeling Smoke PlumeRise and Dispersion from Southern United States Pre- scribed Burns with Daysmoke, Atmosphere, 2, 358-388, https://doi.org/10.3390/atmos2030358, 2011.

Boersma, K. F., Eskes, H. J., Veefkind, J. P., Brinksma, E. J., van der A, R. J., Sneep, M., van den Oord, G. H. J., Levelt, P. F., Stammes, P., Gleason, J. F., and Bucsela, E. J.: Near-real time retrieval of tropospheric NO2 from OMI, Atmos. Chem. Phys., 7, 2103-2118, https://doi.org/10.5194/acp-7-2103-2007, 2007

Briggs, G. A.: A plume rise model compared with observations, Journal of the Air Pollution Control Association, 15, 433-438, https://doi.org/10.1080/00022470.1965.10468404, 1965.

Buchard, V., da Silva, A. M., Colarco, P. R., Darmenov, A., Randles, C. A., Govindaraju, R., Torres, O., Campbell, J., and Spurr, R.: Using the OMI aerosol index and absorption aerosol optical depth to evaluate the NASA MERRA Aerosol Reanalysis, Atmos. Chem. Phys., 15, 5743-5760, https://doi.org/10.5194/acp15-5743-2015.

Chew, B. N., Campbell, J. R., Salinas, S. V., Chang, C., W., Reid, J. S., Welton, E. J., and Liew, S. C.: Aerosol particle vertical distributions and optical properties over Singapore, Atmos. Environ., 79, 599-613, https://doi.org/10.1016/j.atmosenv.2013.06.026, 2013.

Cohen, J. B.: Quantifying the occurrence and magnitude of the Southeast Asian fire climatology, Environ. Res. Lett., 9, 114018, https://doi.org/10.1088/1748-9326/9/11/114018, 2014.

Cohen, J. B. and Prinn, R. G.: Development of a fast, urban chemistry metamodel for inclusion in global models, Atmos. Chem. Phys., 11, 7629-7656, https://doi.org/10.5194/acp-117629-2011, 2011.

Cohen, J. B. and Wang, C.: Estimating global black carbon emissions using a top-down Kalman Filter approach, J. Geophys. Res.-Atmos., 119, 307-323, https://doi.org/10.1002/2013JD019912, 2014.

Cohen, J. B., Prinn, R. G., and Wang, C.: The Impact of detailed urban-scale processing on the composition, distribution, and radiative forcing of anthropogenic aerosols, Geophys. Res. Lett., 38, L10808, https://doi.org/10.1029/2011GL047417, 2011.

Cohen, J. B., Lecoeur, E., and Hui Loong Ng, D.: Decadal-scale relationship between measurements of aerosols, land-use change, and fire over Southeast Asia, Atmos. Chem. Phys., 17, 721-743, https://doi.org/10.5194/acp-17-721-2017, 2017.

Cohen, J. B., Ng, D. H. L., Lim, A. W. L., and Chua, X. R.: Vertical distribution of aerosols over the Maritime Continent during El Niño, Atmos. Chem. Phys., 18, 7095-7108, https://doi.org/10.5194/acp-18-7095-2018, 2018.

Damoah, R., Spichtinger, N., Servranckx, R., Fromm, M., Eloranta, E. W., Razenkov, I. A., James, P., Shulski, M., Forster, C., and Stohl, A.: A case study of pyro-convection using transport model and remote sensing data, Atmos. Chem. Phys., 6, 173185, https://doi.org/10.5194/acp-6-173-2006, 2006.

Deeter, M. N., Edwards, D. P., Francis, G. L., Gille, J. C., Martínez-Alonso, S., Worden, H. M., and Sweeney, C.: A climate-scale satellite record for carbon monoxide: the MOPITT Version 7 product, Atmos. Meas. Tech., 10, 2533-2555, https://doi.org/10.5194/amt-10-2533-2017, 2017.

DeWitt, H. L., Gasore, J., Rupakheti, M., Potter, K. E., Prinn, R. G., Ndikubwimana, J. D. D., Nkusi, J., and Safari, B.: Seasonal and diurnal variability in $\mathrm{O}_{3}$, black carbon, and $\mathrm{CO}$ measured at the Rwanda Climate Observatory, Atmos. Chem. Phys., 19, 2063 2078, https://doi.org/10.5194/acp-19-2063-2019, 2019. 
Field, R. D., van der Werf, G. R., and Shen S. P. P.: Human amplification of drought-induced biomass burning in Indonesia since 1960, Nat. Geosci., 2, 185-188, https://doi.org/10.1038/ngeo443, 2009.

Flower, V. J. B. and Kahn, R. A.: Assessing the altitude and dispersion of volcanic plumes using MISR multi-angle imaging from space: Sixteen years of volcanic activity in the Kamchatka Peninsula, Russia, J. Volcanol. Geoth. Res., 337, 1-15, https://doi.org/10.1016/j.jvolgeores.2017.03.010, 2017.

Freeborn, P. H., Wooster, M. J., Roy, D. P., and Cochrane, M. A.: Quantification of MODIS fire radiative power (FRP) measurement uncertainty for use in satellite-based active fire characterization and biomass burning estimation, Geophys. Res. Lett., 41, 1988-1994, https://doi.org/10.1002/2013GL59086, 2014.

Freitas, S. R., Longo, K. M., Chatfield, R., Latham, D., Silva Dias, M. A. F., Andreae, M. O., Prins, E., Santos, J. C., Gielow, R., and Carvalho Jr., J. A.: Including the sub-grid scale plume rise of vegetation fires in low resolution atmospheric transport models, Atmos. Chem. Phys., 7, 3385-3398, https://doi.org/10.5194/acp7-3385-2007, 2007.

Generoso, S., Bey, I., Atti, J.-L., and Bron, F.-M.: A satelliteand model-based assessment of the 2003 Russian fires: Impact on the Arctic region, J. Geophys. Res., 112, D15302, https://doi.org/10.1029/2006JD008344, 2007.

Giglio, L., Csiszar, I., and Justice, C. O.: Global distribution and seasonality of active fires as observed with the Terra and Aqua Moderate Resolution Imaging Spectroradiometer (MODIS) sensors, J. Geophys. Res., 111, G02016, https://doi.org/10.1029/2005JG000142, 2006.

GMAO (Global Modeling and Assimilation Office): MERRA2 inst3_3d_aer_Nv: 3d, 3-Hourly, Instantaneous, Model-Level, Assimilation, Aerosol Mixing Ratio V5.12.4, Greenbelt, MD, USA, Goddard Earth Sciences Data and Information Services Center (GES DISC), https://doi.org/10.5067/LTVB4GPCOTK2, 2015.

Gonzalez-Alonso, L., Val Martin, M., and Kahn, R. A.: Biomass-burning smoke heights over the Amazon observed from space, Atmos. Chem. Phys., 19, 1685-1702, https://doi.org/10.5194/acp-19-1685-2019, 2019.

Grandey, B. S., Rothenberg, D., Avramov, A., Jin, Q., Lee, H.-H., Liu, X., Lu, Z., Albani, S., and Wang, C.: Effective radiative forcing in the aerosol-climate model CAM5.3-MARC-ARG, Atmos. Chem. Phys., 18, 15783-15810, https://doi.org/10.5194/acp-1815783-2018, 2018.

Gunturu, U. B.: Aerosol-Cloud Interactions: A New Perspective in Precipitation Enhancement, $\mathrm{PhD}$ thesis, Massachusetts Institute of Technology, 2010.

Guo, J., Deng, M., Lee, S. S., Wang, F., Li, Z., Zhai, P., Liu, H., Lv, W., Yao W., and Li X.: Delaying precipitation and lightning by air pollution over the Pearl River Delta. Part I: Observational analyses, J. Geophys. Res., 121, 6472-6488, https://doi.org/10.1002/2015JD023257, 2016.

Guo, J., Li, Y., Cohen, J. B., Li, J., Chen, D., Xu, H., Liu, L., Yin, J., Hu, K., and Zhai, P.: Shift in the temporal trend of boundary layer height trend in China using long-term (19792016) radiosonde data, Geophys. Res. Lett., 46, 6080-6089, https://doi.org/10.1029/2019GL082666, 2019.

He, Q., Qin, K., Cohen, J. B., Loyola, D., Li, D., Shi, J., and Xue, Y.: Spatially and temporally coherent reconstruction of tropospheric
$\mathrm{NO}_{2}$ over China combining OMI and GOME-2B measurements, Environ. Res. Lett., online first, https://doi.org/10.1088/17489326/abc7df, 2020

Heald, C. L., Jacob, D. J., Jones, D. B. A., Palmer, P. I., Logan, J. A., Streets, D. G., Sachse, G. W., Gille, J. C., Hoffman, R. N., and Nehrkorn, T.: Comparative inverse analysis of satellite (MOPITT) and aircraft (TRACE-P) observations to estimate Asian sources of carbon monoxide, J. Geophys. Res., 109, D23306, https://doi.org/10.1029/2004JD005185, 2004.

Husar, R. B., Prospero, J. M., and Stowe, L. L.: Characterization of tropospheric aerosols over the oceans with the NOAA advanced very high resolution radiometer optical thickness operational product, J. Geophys. Res., 102, 16889-16909, https://doi.org/10.1029/96jd04009, 1997.

Ichoku, C. and Ellison, L.: Global top-down smoke-aerosol emissions estimation using satellite fire radiative power measurements, Atmos. Chem. Phys., 14, 6643-6667, https://doi.org/10.5194/acp-14-6643-2014, 2014

Ichoku, C., Giglio, L., Wooster, M., and Remer, L.: Global characterization of biomass-burning patterns using satellite measurements of fire radiative energy, Remote Sens. Environ., 112, 2950-2962, https://doi.org/10.1016/j.rse.2008.02.009, 2008.

Jost, H., Drdla, K., Stohl, A., Pfister, L., Loewenstein, M., Lopez, J. P., Hudson, P. K., Murphy, D. M., Cziczo, D. J., Fromm, M., Bui, T. P., Dean-Day, J., Gerbig, C., Mahoney, M. J., Richard, E. C., Spichtinger, N., Pittman, V. J., Weinstock, E. M., Wilson, J. C., and Xueref, I.: In-situ observations of mid-latitude forest fire plumes deep in the stratosphere, Geophys. Res. Lett., 31, L11101, https://doi.org/10.1029/2003GL019253, 2004.

Kahn, R.: A Global Perspective on Wildfires, Eos, 101, https://doi.org/10.1029/2020EO138260, 2020.

Kahn, R. A., Li, W. H., Moroney, C., Diner, D. J., Martonchik, J. V., and Fishbein, E.: Aerosol source plume physical characteristics from space-based multiangle imaging, J. Geophys. Res., 112, D11205, https://doi.org/10.1029/2006JD007647, 2007.

Kahn, R. A., Chen, Y., Nelson, D. L., Leung, F. Y., Li, Q., Diner, D. J., and Logan, J. A..: Wildfire smoke injection heights: Two perspectives from space, Geophys. Res. Lett., 35, L04809, https://doi.org/10.1029/2007GL032165, 2008.

Kaiser, J. W., Heil, A., Andreae, M. O., Benedetti, A., Chubarova, N., Jones, L., Morcrette, J.-J., Razinger, M., Schultz, M. G., Suttie, M., and van der Werf, G. R.: Biomass burning emissions estimated with a global fire assimilation system based on observed fire radiative power, Biogeosciences, 9, 527-554, https://doi.org/10.5194/bg-9-527-2012, 2012.

Kalnay, E., Kanamitsu, M., Kistler, R., Collins, W., Deaven, D., Gandin, L., Iredell, M., Saha, S., White, G., Woollen, J., Zhu, Y., Chelliah, M., Ebisuzaki, W., Higgins, W., Janowiak, J., Mo, K. C., Ropelewski, C., Wang, J., Leetmaa, A., Reynolds, R., Jenne, R., and Joseph, D.: NCEP/NCAR 40-year reanalysis project, B. Am. Meteorol. Soc., 77, 437-472, https://doi.org/10.1175/15200477(1996)077<0437:TNYRP>2.0.CO;2, 1996.

Kauffman, J. B., Steele, M. D., Cummings D. L., and Jaramillo V. J.: Biomass dynamics associated with deforestation, fire, and, conversion to cattle pasture in a Mexican tropical dry forest, Forest Ecol. Manag., 176, 1-12, https://doi.org/10.1016/s03781127(02)00227-x, 2003.

Kim, D., Wang, C., Ekman, A. M. L., Barth, M. C., and Rasch, P.: Distribution and direct radiative forcing of car- 
bonaceous and sulfate aerosols in an interactive size-resolving aerosol-climate model, J. Geophys. Res., 113, D16309, https://doi.org/10.1029/2007JD009756, 2008.

Labonne, M., Breìon, F.-M., and Chevallier, F.: Injection height of biomass burning aerosols as seen from a spaceborne lidar, Geophys. Res. Lett., 34, L11806, https://doi.org/10.1029/2007GL029311, 2007.

Lamsal, L. N., Martin, R. V., Padmanabhan, A., van Donkelaar, A., Zhang, Q., Sioris, C. E., Chance, K., Kurosu, T. P., and Newchurch, M. J.: Application of satellite observations for timely updates to global anthropogenic $\mathrm{NO}_{x}$ emission inventories, Geophys. Res. Lett., 38, L05810, https://doi.org/10.1029/2010GL046476, 2011.

Lamsal, L. N., Krotkov, N. A., Marchenko, S. V., Joiner, J., Oman, L., Vasilkov, A., Fisher, B., Qin, W., Yang, E.S., Fasnacht, Z., Choi, S., Leonard, P., and Haffner, D.: OMI/Aura NO2 Tropospheric, Stratospheric \& Total Columns MINDS Daily L3 Global Gridded 0.25 degree x 0.25 degree, NASA Goddard Space Flight Center, Goddard Earth Sciences Data and Information Services Center (GES DISC), https://doi.org/10.5067/MEASURES/MINDS/DATA301, 2020.

Leung, F. Y. T., Logan, J. A., Park, R., Hyer, E., Kasischke, E., Streets, D., and Yurganov, L.: Impacts of enhanced biomass burning in the boreal forests in 1998 on tropospheric chemistry and the sensitivity of model results to the injection height to emissions, J. Geophys. Res., 112, D10313, https://doi.org/10.1029/2006JD008132, 2007.

Levelt, P. F., van den Oord, G. H. J., Dobber, M. R., Malkki, A., Visser, H., de Vries, J., Stammes, P., Lundell, J. O. V., and Saari, H.: The ozone monitoring instrument, IEEE T. Geosci. Remote, 44, 1093-1101, https://doi.org/10.1109/TGRS.2006.872333, 2006.

Lin, C. Y., Cohen, J. B., Wang, S., and Lan, R. Y.: Application of a combined standard deviation and mean based approach to MOPITT CO column data, and resulting improved representation of biomass burning and urban air pollution sources, Remote Sens. Environ., 241, 11720, https://doi.org/10.1016/j.rse.2020.111720, 2020a.

Lin, C. Y., Cohen, J. B., Wang, S., Lan, R. Y., and Deng W. Z.: A new perspective on the spatial, temporal, and vertical distribution of biomass burning: quantifying a significant increase in CO emissions, Environ. Res. Lett., 15 104091, https://doi.org/10.1088/1748-9326/abaa7a, 2020b.

Lin, N. H., Sayer, A. M., Wang, S. H., Loftus, A. M., Hsiao, T. C., Sheu, G. R., and Chantara, S.: Interactions between biomassburning aerosols and clouds over Southeast Asia: Current status, challenges, and perspectives, Environ. Pollut., 195, 292-307, https://doi.org/10.1016/j.envpol.2014.06.036, 2014.

Mims, S. R., Kahn, R. A., Moroney, C. M., Gaitley, B. J., Nelson, D. L., and Garay, M. J.: MISR stereo-heights of grassland fire smoke plumes in Australia, IEEE T. Geosci. Remote, 48, 25-35, https://doi.org/10.1109/TGRS.2009.2027114, 2010.

Ming, Y., Ramaswamy, V., and Persad, G.: Two opposing effects of absorbing aerosols on global-mean precipitation, Geophys. Res. Lett., 37, L13701, https://doi.org/10.1029/2010GL042895, 2010.

NASA/LARC/SD/ASDC: MOPITT CO gridded daily means (Near and Thermal Infrared Radiances) V008, NASA Langley Atmospheric Science Data Center DAAC,
https://doi.org/10.5067/TERRA/MOPITT/MOP03J_L3.008, 2000.

Nelson, D. L., Garay M. J., Kahn R. A., and Dunst B. A.: Stereoscopic Height and Wind Retrievals for Aerosol Plumes with the MISR INteractive eXplorer (MINX), Remote Sens., 5, 45934628, https://doi.org/10.3390/rs5094593, 2013.

Nelson, D., Val, S.,Kahn, R., Koeberlein, E., Tosca, M., Diner, D., and Lawshe, C.: MISR plume height project, available at: https:// misr.jpl.nasa.gov/getData/accessData/ (last access: 1 September 2019), 2015.

NOAA/OAR/ESRL PSL: NCEP/NCAR Reanalysis 1: Summary, NOAA/OAR/ESRL PSL, Boulder, Colorado, USA, available at: https://psl.noaa.gov/data/gridded/data.ncep.reanalysis.html (last access: 1 September 2019), 1996.

Palacios-Orueta, A., Chuvieco, E., Parra, A., and Carmona-Moreno, C.: Biomass Burning Emissions: A Review of Models Using Remote-Sensing Data, Environ. Monit. Assess., 104, 189-209, https://doi.org/10.1007/s10661-005-1611-y, 2005.

Paugam, R., Wooster, M., Freitas, S., and Val Martin, M.: A review of approaches to estimate wildfire plume injection height within large-scale atmospheric chemical transport models, Atmos. Chem. Phys., 16, 907-925, https://doi.org/10.5194/acp-16907-2016, 2016.

Petersen, W. and Rutledge, S.: Regional variability in tropical convection: observations from TRMM, J. Climate, 14 , 3566-3586, https://doi.org/10.1175/15200469(1989)046<0037:OOLFOI>2.0.CO;2, 2001.

Petrenko, M., Kahn, R. A., Chin, M., Soja, A. J., Kucsera, T., and Harshvardhan: The use of satellite-measured aerosol optical depth to constrain biomass burning emissions source strength in the global model GOCART, J. Geophys. Res., 117, D18212, https://doi.org/10.1029/2012JD017870, 2012.

Pfister, G. G., Wiedinmyer, C., and Emmons, L. K.: Impacts of the fall 2007 California wildfires on surface ozone: Integrating local observations with global model simulations, Geophys. Res. Lett., 35, L19814, https://doi.org/10.1029/2008GL034747, 2008.

Ramanathan, V., Ramana, M. V., Roberts, G., Kim, D., Corrigan, C., Chung, C., and Winker, D.: Warming trends in Asia amplified by brown cloud solar absorption, Nature, 448, 575-578, https://doi.org/10.1038/nature06019, 2007.

Randles, C., Da Silva, A., Buchard, V., Colarco, P., Darmenov, A., Govindaraju, R., Smirnov, A., Holben, B., Ferrare, R., and Hair, J.: The MERRA-2 aerosol reanalysis, 1980 onward. Part I: system description and data assimilation evaluation, J. Climate, 30, 6823-6850, 2017.

Reid, J. S., Hyer, E. J., Johnson, R. S., Holben, B. N., Yokelson, R. J., Zhang, J., Campbell, J. R., Christopher, S. A., Di Girolamo, L., Giglio, L., Holz, R. E., Kearney, C., Miettinen, J., Reid, E. A., Turk, F. J., Wang, J., Xian, P., Zhao, G., Balasubramanian, R., Chew, B. N., Janjai, S., Lagrosas, N., Lestari, P., Lin, N.H., Mahmud, M., Nguyen, A. X., Norris, B., Oanh, N. T. K., Oo, M., Salinas, S. V., Welton, E. J., and Liew, S. C.: Observing and understanding the Southeast Asian aerosol system by remote sensing: An initial review and analysis for the Seven Southeast Asian Studies (7SEAS) program, Atmos. Res., 122, 403-468, https://doi.org/10.1016/j.atmosres.2012.06.005, 2013

Rogers, R. R., Hostetler, C. A., Hair, J. W., Ferrare, R. A., Liu, Z., Obland, M. D., Harper, D. B., Cook, A. L., Powell, K. A., Vaughan, M. A., and Winker, D. M.: Assessment of the 
CALIPSO Lidar $532 \mathrm{~nm}$ attenuated backscatter calibration using the NASA LaRC airborne High Spectral Resolution Lidar, Atmos. Chem. Phys., 11, 1295-1311, https://doi.org/10.5194/acp11-1295-2011, 2011.

Seinfeld, J. H. and Pandis, S. N.: Atmospheric Chemistry and Physics: From Air Pollution to Climate Change, Wiley, New York, 1326 pp., ISBN: 0-471-17815-2, 1998.

Singh, N., Banerjee, T., Raju, M. P., Deboudt, K., Sorek-Hamer, M., Singh, R. S., and Mall, R. K.: Aerosol chemistry, transport, and climatic implications during extreme biomass burning emissions over the Indo-Gangetic Plain, Atmos. Chem. Phys., 18, 1419714215, https://doi.org/10.5194/acp-18-14197-2018, 2018

Sofiev, M., Ermakova, T., and Vankevich, R.: Evaluation of the smoke-injection height from wild-land fires using remote-sensing data, Atmos. Chem. Phys., 12, 1995-2006, https://doi.org/10.5194/acp-12-1995-2012, 2012.

Spracklen, D. V., Mickley, L. J., Logan, J. A., Hudman, R. C., Yevich, R., Flannigan, M. D., and Westerling A. L.: Impacts of climate change from 2000 to 2050 on wildfire activity and carbonaceous aerosol concentrations in the western United States, J. Geophys. Res.,114, D20301, https://doi.org/10.1029/2008JD010966, 2009.

Tao, W.-K., Chen, J.-P., Li, Z., Wang, C., and Zhang, C.: Impact of aerosols on convective clouds and precipitation, Rev. Geophys., 50, RG2001, https://doi.org/10.1029/2011RG000369, 2012.

Tosca, M. G., Randerson, J. T., Zender, C. S., Nelson, D. L., Diner, D. J., and Logan, J. A.: Dynamics of fire plumes and smoke clouds associated with peat and deforestation fires in Indonesia, J. Geophys. Res., 116, D08207, https://doi.org/10.1029/2010JD015148, 2011.

Trentmann, J., Luderer, G., Winterrath, T., Fromm, M. D., Servranckx, R., Textor, C., Herzog, M., Graf, H.-F., and Andreae, M. O.: Modeling of biomass smoke injection into the lower stratosphere by a large forest fire (Part I): reference simulation, Atmos. Chem. Phys., 6, 5247-5260, https://doi.org/10.5194/acp6-5247-2006, 2006.

Tsigaridis, K., Daskalakis, N., Kanakidou, M., Adams, P. J., Artaxo, P., Bahadur, R., Balkanski, Y., Bauer, S. E., Bellouin, N., Benedetti, A., Bergman, T., Berntsen, T. K., Beukes, J. P., Bian, H., Carslaw, K. S., Chin, M., Curci, G., Diehl, T., Easter, R. C., Ghan, S. J., Gong, S. L., Hodzic, A., Hoyle, C. R., Iversen, T., Jathar, S., Jimenez, J. L., Kaiser, J. W., Kirkevåg, A., Koch, D., Kokkola, H., Lee, Y. H., Lin, G., Liu, X., Luo, G., Ma, X., Mann, G. W., Mihalopoulos, N., Morcrette, J.-J., Müller, J.-F., Myhre, G., Myriokefalitakis, S., Ng, N. L., O’Donnell, D., Penner, J. E., Pozzoli, L., Pringle, K. J., Russell, L. M., Schulz, M., Sciare, J., Seland, Ø., Shindell, D. T., Sillman, S., Skeie, R. B., Spracklen, D., Stavrakou, T., Steenrod, S. D., Takemura, T., Tiitta, P., Tilmes, S., Tost, H., van Noije, T., van Zyl, P. G., von Salzen, K., Yu, F., Wang, Z., Wang, Z., Zaveri, R. A., Zhang, H., Zhang, K., Zhang, Q., and Zhang, X.: The AeroCom evaluation and intercomparison of organic aerosol in global models, Atmos. Chem. Phys., 14, 10845-10895, https://doi.org/10.5194/acp-1410845-2014, 2014.
Turquety, S., Logan, J. A., Jacob, D. J., Hudman, R. C., Leung, F. Y., Heald, C. L., Yantosca, R. M., Wu, S., Emmons, L. K., Edwards, D. P., and Sachse, G. W.: Inventory of boreal fire emissions for North America in 2004: Importance of peat burning and pyroconvective injection, J. Geophys. Res., 112, D12S03, https://doi.org/10.1029/2006JD007281, 2007.

Urbanski, S.: Wildland fire emissions, carbon, and climate: Emission factors, Forest Ecol. Manage., 317, 51-60, https://doi.org/10.1016/j.foreco.2013.05.045, 2014.

Val Martin, M., Logan, J. A., Kahn, R. A., Leung, F.-Y., Nelson, D. L., and Diner, D. J.: Smoke injection heights from fires in North America: analysis of 5 years of satellite observations, Atmos. Chem. Phys., 10, 1491-1510, https://doi.org/10.5194/acp10-1491-2010, 2010.

Val Martin, M., Kahn, R. A., Logan, J. A., Paugam, R., Wooster, M., and Ichoku, C.: Space-based observational constraints for 1D fire smoke plume-rise models, J. Geophys. Res., 117, D22204, https://doi.org/10.1029/2012JD018370, 2012.

Val Martin, M., Kahn, R. A., and Tosca, M.: A Global Analysis of Wildfire Smoke Injection Heights Derived from Space-Based Multi-Angle Imaging, Remote Sens., 10, 1609, https://doi.org/10.3390/rs10101609, 2018.

Vernon, C. J., Bolt, R., Canty, T., and Kahn, R. A.: The impact of MISR-derived injection height initialization on wildfire and volcanic plume dispersion in the HYSPLIT model, Atmos. Meas. Tech., 11, 6289-6307, https://doi.org/10.5194/amt11-6289-2018, 2018.

Wang, C.: The sensitivity of tropical convective precipitation to the direct radiative forcings of black carbon aerosols emitted from major regions, Ann. Geophys., 27, 3705-3711, https://doi.org/10.5194/angeo-27-3705-2009, 2009.

Wang, S. and Cohen, J.: model results for PRM and RM, Dataset, figshare, https://doi.org/10.6084/m9.figshare.10252526.v1, 2019.

Wang, S. and Cohen, J.: MERRA data, Dataset, figshare, https://doi.org/10.6084/m9.figshare.12386135.v1, 2020.

Winker, D. M., Tackett, J. L., Getzewich, B. J., Liu, Z., Vaughan, M. A., and Rogers, R. R.: The global 3-D distribution of tropospheric aerosols as characterized by CALIOP, Atmos. Chem. Phys., 13, 3345-3361, https://doi.org/10.5194/acp-133345-2013, 2013.

Yu, P. F., Toon, O. B., Bardeen, C. G., Zhu, Y. Q., Rosenlof, K. H., Portmann, R. W., Thornberry, T. D., Gao, R. S., Davis, S. M., Wolf, E. T., Gouw, J., Peterson, D. A., Fromm, M. D., and Robock, A.: Black carbon lofts wildfire smoke high into the stratosphere to form a persistent plume, Science, 365, 587-590, https://doi.org/10.1126/science.aax1748, 2019.

Zhu, L., Val Martin, M., Gatti, L. V., Kahn, R., Hecobian, A., and Fischer, E. V.: Development and implementation of a new biomass burning emissions injection height scheme (BBEIH v1.0) for the GEOS-Chem model (v9-01-01), Geosci. Model Dev., 11, 4103-4116, https://doi.org/10.5194/gmd-114103-2018, 2018 